\title{
Systematic review of effects on biodiversity from oil palm production
}

Sini Savilaakso

Claude Garcia

John Garcia-Ulloa

Jaboury Ghazoul

Martha Groom

Manuel R Guariguata

Yves Laumonier

Robert Nasi

Gillian Petrokofsky

Jake Snaddon

Michal Zrust

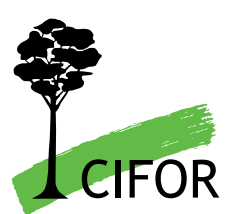




\title{
Systematic review of effects on biodiversity from oil palm production
}

\author{
Sini Savilaakso \\ CIFOR \\ Claude Garcia \\ Department of Environmental Systems Science, ETH Zurich, Switzerland \\ CIRAD, Research Unit Goods and Services of Tropical Forest Ecosystems \\ John Garcia-Ulloa \\ Department of Environmental Systems Science, ETH Zurich, Switzerland \\ Jaboury Ghazoul \\ Department of Environmental Systems Science, ETH Zurich, Switzerland

\section{Martha Groom} \\ Interdisciplinary Arts and Sciences, University of Washington \\ Program on the Environment, University of Washington \\ Manuel R Guariguata \\ CIFOR \\ Yves Laumonier \\ CIFOR \\ Research Unit Goods and Services of Tropical Forest Ecosystems, CIRAD
}

Robert Nasi

CIFOR

Gillian Petrokofsky

Biodiversity Institute, Department of Zoology, University of Oxford

Jake Snaddon

Biodiversity Institute, Department of Zoology, University of Oxford

Michal Zrust

Zoological Society of London, Indonesia Programme 
Occasional Paper 116

(c) 2014 Center for International Forestry Research

(c) (1) Content in this publication is licensed under a Creative Commons Attribution 4.0 International (CC BY 4.0), http://creativecommons.org/licenses/by/4.0/

ISBN 978-602-1504-72-7

Savilaakso S, Garcia C, Garcia-Ulloa J, Ghazoul J, Groom M, Guariguata MR, Laumonier Y, Nasi R, Petrokofsky G, Snaddon J and Zrust M. 2014. Systematic review of effects on biodiversity from oil palm production. Occasional Paper 116. Bogor, Indonesia: CIFOR.

This publication was first published in Environmental Evidence 2014, 3:4.

http://www.environmentalevidencejournal.org/content/3/1/4

Photo by Jake Snaddon

\author{
CIFOR \\ Jl. CIFOR, Situ Gede \\ Bogor Barat 16115 \\ Indonesia \\ $\mathrm{T}+62(251) 8622-622$ \\ $F+62$ (251) 8622-100 \\ E cifor@cgiar.org
}

\title{
cifor.org
}

We would like to thank all donors who supported this research through their contributions to the CGIAR Fund. For a list of Fund donors please see: https://www.cgiarfund.org/FundDonors

Any views expressed in this publication are those of the authors. They do not necessarily represent the views of CIFOR, the editors, the authors' institutions, the financial sponsors or the reviewers. 


\section{Table of contents}

$\begin{array}{ll}\text { Acknowledgments } & \text { v }\end{array}$

Background 1

Objective of the review 1

Methods $\quad 2$

2.1 Search strategy 2

2.2 Study inclusion criteria 3

2.3 Potential effect modifiers and study quality assessment 4

2.4 Data extraction and synthesis 4

$\begin{array}{ll}\text { Results } & 6\end{array}$

3.1 Review statistics $\quad 6$

3.2 Description of studies $\quad 6$

$\begin{array}{ll}3.3 & \text { Quantitative synthesis } \\ 3.41\end{array}$

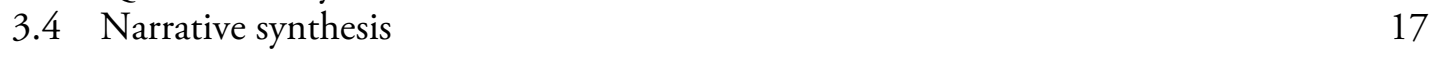

$\begin{array}{lr}\text { Discussion } & 18\end{array}$

$\begin{array}{lll}4.1 & \text { Evidence of impact } & 18\end{array}$

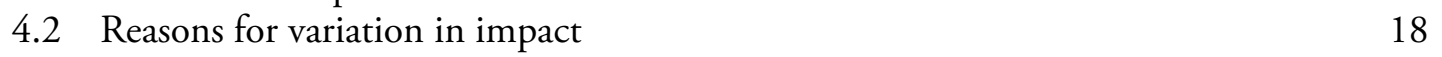

$\begin{array}{ll}4.3 \text { Review limitations } & 19\end{array}$

Conclusions $\quad \mathbf{2 0}$

5.1 Potential implications for biodiversity conservation, policy, and
plantation management

5.2 Potential implications for research 20

$\begin{array}{lr}\text { References } & 21\end{array}$

Appendices $\quad \mathbf{2 4}$

1. Search terms in different languages 24

2. Equations used in the quantitative meta-analysis 25

3. List of studies included in the review 26

4. Qualitative assessment of standards related to oil palm, jatropha, and soybean 28 


\section{List of figures and tables}

\section{Figures}

1. The number of articles at different assessment stages. 6

2. Number of articles published in different years. $\quad 7$

3. Taxonomic groups studied in the 25 studies on biodiversity included in the review. $\quad 7$

4. The size of plantations studied. $\quad 8$

5. Forest plot of effect sizes for species richness (mean standardized difference between primary forest and oil palm plantation).

6. Forest plot of effect sizes for species richness (mean standardized difference between secondary forest and oil palm plantation).

7. Forest plot of effect sizes for abundance of individuals (mean standardized difference between primary forest and oil palm plantation).

8. Forest plot of effect sizes for abundance of individuals (mean standardized difference between secondary forest and oil palm plantation).

9. Mean proportion of shared species between oil palm plantation and forest with $95 \%$ confidence intervals.

\section{Tables}

1. Search terms in different categories.

2. Hierarchy of quality of evidence based on the information provided in the documents.

3. Summary of methods used in the studies included in the review.

4. Summary of information on species composition provided in the reviewed studies.

5. Summary of information on species composition between logged peat forest and smallholder plantations.

6. Total species richness in forests and plantations, the number of shared species, and the proportion of species remaining. 


\section{Acknowledgments}

We thank all the authors who responded to our queries and provided additional information. We acknowledge our superb librarian, Wiwit Siswarini, for her help in finding articles and other information resources. We are thankful for Bruno Locatelli for his guidance on statistical issues but note that he bears no responsibility for any of our decisions regarding the statistics. We thank Ankara M Chen for her help in organizing the superb workshop in Zürich that provided the push to finalize the review. We acknowledge Wen Zhou for her support. Three anonymous reviewers provided useful suggestions to improve the protocol to conduct this systematic review. We thank Andrew Pullin and two anonymous reviewers for their comments, which gave the final review more focus and improved its quality. The review was supported by the Center for International Forestry Research, the Government of Finland, ETH Zürich, and CIRAD. 



\section{Background}

Over the last decade there has been a growing interest in bioenergy, especially biofuels, that has been driven by concerns about global climate change, increasing energy demand, and reducing dependence on fossil fuels (Rajagopal and Zilberman 2007). Energy derived from plant material, such as sugarcane and oil palm, offers, at least in theory, a promising way to answer energy demand without increasing greenhouse gas (GHG) emissions. In addition, biofuel production can create additional income for the rural poor and advance economic development (Feintrenie et al. 2010).

Nevertheless, biofuel-based opportunities do not come without concerns. Direct or indirect land use change resulting from expansion of biofuel cultivation can cause deforestation and destroy natural habitats (Lewandowski and Faaij 2006, Koh and Ghazoul 2008), which in turn may lead to the loss of biodiversity (Danielsen et al. 2009, Phalan 2009). Reduced biodiversity may have further negative impacts on ecosystem functions (Aerts and Honnay 2011).

To respond to concerns about the potential negative social and environmental impacts, several voluntary standards have emerged since the beginning of the millennium. The most prominent have emerged from the Roundtable on Sustainable Palm Oil (RSPO), which was formally established in 2004, the Roundtable on Responsible Soy Association (RRSA) in 2006, and the Roundtable on Sustainable Biofuels (RSB) in 2007. There have also been legislative efforts (e.g. Directive 2009/28/EC of the European Parliament and of the Council) to ensure that the production of imported biofuels is considered sustainable. However, there have been concerns that the standards are not effective enough to reduce the threat biofuel production poses to tropical forest ecosystems (Laurance et al. 2010).
Currently, palm oil and soybean are produced mainly for food, and thus cultivation for biofuel production has contributed little to the land use change patterns for these crops (Rajagopal and Zilberman 2007, Phalan 2009). Nevertheless, biofuel production has been predicted to grow (FAO 2008) and it is important to know what the potential consequences of expanding biofuel cultivation are for biodiversity and biodiversity-related ecosystem functions, and to understand how well the standards in their current form might help to mitigate those impacts.

\section{Objective of the review}

The purpose of this review was to assess objectively the current state of knowledge of the impact of three first-generation biofuel crops (oil palm, soybean, and jatropha) on biodiversity in the tropics. The focus was on the direct impacts of forest conversion for crop plantations (resulting in forest fragmentation and deforestation) on species richness, abundance (i.e. overall number of individuals or occurrences) and community composition, and on ecosystem functions related to biodiversity (such as pollination, seed dispersal, biocontrol, nutrient cycling, soil fertility, and decomposition). In addition to impacts, different standards related to oil palm, jatropha, and soybean were assessed for their potential to mitigate the impacts. The specific study questions were:

- Does cultivation of oil palm, soybean, and jatropha in the tropics lead to the loss of biodiversity and ecosystem functions due to deforestation and fragmentation?

- Is there a difference in the impacts on biodiversity between industrial plantations and smallholder plantations per volume of fuel produced?

- Do different standards related to oil palm, jatropha and soybean mitigate the negative impacts? 


\section{Methods}

\subsection{Search strategy}

\subsubsection{Design of the review}

An a priori protocol was established, peer reviewed and posted on the website of the Collaboration for Environmental Evidence (CEE) after acceptance by CEE (Savilaakso et al. 2013). The protocol was followed with one change: the secondary study question on standards was revised after publication of the protocol and is presented in this review in the form used.

\subsubsection{Search sources}

The original literature search was conducted between May and November 2011 and updated between October and November 2012 to retrieve articles published after November 2011. The search included academic literature databases, internet search engines, as well as websites of specialist organizations. In addition, bibliographies of articles included in the review and previously published reviews were checked for references. The following is the full list of sources searched:

\section{Literature databases}

- Biofuels abstracts database by CAB

- Directory of Open Access Journals

- Web of Science

\section{Internet search engines}

- Google: www.google.com

- Google Scholar: www.scholar.google.com

- Scirus: www.scirus.com

\section{Websites of specialist organizations}

- European Biofuels Technology Platform: www. biofuelstp.eu,

- Center for International Forestry Research: www.cifor.org

- Food and Agriculture Organization of the United Nations: www.fao.org
- Forest Trends: www.forest-trends.org

- Global Bioenergy Partnership: www. globalbioenergy.org

- The International Fund for Agricultural Development: www.ifad.org

- International Finance Corporation: www.ifc.org

- International Food Policy Research Institute: www.ifpri.org

- International Institute for Environment and Development: www.iied.org

- International Union for Conservation of Nature: www.iucn.org

- WWF: www.panda.org

- Rainforest Alliance: www.rainforest-alliance.org

- Rights and Resources Initiative: www. rightsandresources.org

- Roundtable on Sustainable Palm Oil: www. rspo.org

- Tropenbos International: www.tropenbos.org

- United Nations Framework Convention on Climate Change: www.unfccc.int

- World Resources Institute: www.wri.org

The internet search engines typically returned several thousand results. Therefore, the searches were restricted to the first fifty hits and links to potentially relevant material were followed only once from the original hit. At the websites of specialist organizations, the search was limited to the publications section of the website if there was one. At the website of the European Biofuels Technology Platform the search was restricted to sustainability articles.

\subsubsection{Search terms and languages}

Search strings were created using three categories (exposure, location, and outcome) with Boolean operators AND between categories and OR within categories (Table 1). No specific search terms were used for the study population, i.e. faunal and floral species, as they are inherent in the outcome 
Table 1. Search terms in different categories.

\begin{tabular}{lll}
\hline Exposure & Location & Outcome \\
\hline Oil palm & & Species diversity \\
Soybean & Tropic* & Species richness \\
Jatropha & & Species abundance \\
& Species similarity \\
& Species composition \\
& Community composition \\
& Deforestation \\
& Land use change \\
& Fragmentation \\
& Habitat loss \\
& Connectivity \\
& Functional diversity \\
& Ecosystem \\
& Displacement \\
\end{tabular}

* Denotes a wildcard character that was used to include alternative word endings.

category. A wildcard character, i.e. the asterisk, was used in the location category to include alternative word endings. When the search string could not be used in its complete form, combinations of the search terms were used so that one term from each three categories was included, e.g. oil palm AND tropic* AND species richness. Owing to the limitations of the search engine, two search strings were used for the Directory of Open Access Journals: (Oil palm OR jatropha OR soybean) AND tropic* and (Oil palm OR jatropha OR soybean) AND tropical. Similarly, only terms Oil palm OR jatropha OR soybean were used at the Forest Trends website to the limitation on the number of words imposed by the search engine. The search terms were also translated into French, Spanish, German, Swedish, and Finnish (Appendix 1) and searches conducted using the same logic.

\subsection{Study inclusion criteria}

In collaboration with stakeholders, a set of inclusion criteria was developed. Studies that had data about relevant subject, exposure and outcome, together with a valid comparator were included if they fulfilled the quality criteria discussed in the section on study quality assessment.

Studies related to the primary study question were included according to the following criteria:

- Geographical location: Study area within the tropics $\left(23.438^{\circ} \mathrm{S}\right.$ to $\left.23.438^{\circ} \mathrm{N}\right)$
- Relevant subject(s): Faunal and floral species

- Type of exposure: Conversion of the land to cultivate oil palm, soybean, and jatropha for any purpose

- Type of comparator: Other land use or land cover (primary forest, logged-over forest, secondary forest (i.e. regrowth forest), scrubland, grassland, cropland). Both before-after and site comparison studies were accepted

- Types of outcome: Change in species richness, abundance (the overall number of individuals or occurrences), community composition, and ecosystem functions (pollination, seed dispersal, biocontrol, and soil processes)

- Types of study: Qualitative and quantitative primary studies as well as descriptive studies and reports.

For the secondary study question ("Is there a difference in the impact on biodiversity between industrial plantations and smallholder plantations per volume of fuel produced?"), location, subjects and outcome were the same, but the types of exposure and comparator were different:

- Type of exposure: Conversion of the land to industrial plantations for the cultivation of biofuel crops

- Type of comparator: Smallholder plantations.

For the secondary study question "Do different standards related to oil palm, jatropha, and soybean mitigate the negative impacts?" the following criteria were used:

- Relevant subject(s): Faunal and floral species

- Types of exposure: Standard in place should mitigate the impact of crop cultivation on biodiversity

- Types of comparator: Standards were compared against each other to clarify how they mitigate the impact on biodiversity

- Types of outcome: Any reported change within and near the production area

- Types of study: Standards related to oil palm, jatropha, and soybean, i.e. international legislation, industry standards, ISO management standards, NGO standards.

Articles were assessed for relevance first by title, as well as keywords if these were available, then by abstract, and finally, by full text. If the inclusion of an article was in doubt in either of the first two stages, the article was included and the suitability determined at a later stage. 
To assess consistency in the use of inclusion criteria a kappa test was performed. Two reviewers applied the inclusion criteria to a random set of 108 articles at the abstract filter stage. The kappa statistic was calculated to measure the level of agreement between the reviewers. A score of 0.704 was achieved, which indicates substantial strength of agreement (Edwards et al. 2002).

\subsection{Potential effect modifiers and study quality assessment}

Studies do not happen in a vacuum and hence, a number of variables that have the potential to affect study outcomes were recorded when available. The focus was on variables that can influence reliability and generalization of the findings. The following variables were recorded:

- Temporal and spatial scale. The temporal and spatial aspects of sampling were recorded, as well as whether sampling effort was evaluated

- Comparator features: before-after or site comparison

- Methodology used to collect data

- Environmental features of the site: soil type, original vegetation, and the type of surrounding landscape

- Variables related to ecological interactions: competition and predation

- Variables related to plantation management: use of herbicides, insecticides, and fertilizers

- Plantation type (industrial versus smallholder), age, size, and certification status.

To avoid misleading conclusions by including studies with inappropriate designs, studies were evaluated according to the hierarchy of quality of evidence (Table 2). Studies that fell into category VI were excluded from analysis.

\subsection{Data extraction and synthesis}

Originally we planned to categorize the data for the analyses using the following five categories: mammals, birds, amphibians and reptiles, invertebrates, and plants. However, as there were relatively few studies overall, the data were not categorized in this way for the analyses.

There were enough data on species richness (i.e. number of species) and abundance (i.e. overall number of individuals or occurrences) to perform meta-analysis. The purpose of meta-analysis is to summarize the results of individual studies quantitatively using specific statistical methods (Arnqvist and Wooster 1995). The concept at the heart of a meta-analysis is the effect size, which is a statistical measure that portrays the magnitude of which a given effect is present in a sample. It makes it possible to determine whether the overall effect is greater than expected by chance (Rosenthal et al. 1994). There are several effect size estimates that measure the standardized mean difference between two samples and are thus suitable for species richness and abundance data. Hedges' $d$ was chosen because it corrects for a small sample size (Rosenberg et al. 1999) (for the equations used in this section see Appendix 2). The heterogeneity of the effect sizes was estimated using the $Q$-statistic. The $I^{2}$-statistic was used to describe the proportion of the observed variance that reflects real differences in effect sizes (Borenstein et al. 2011).

To perform a quantitative meta-analysis on species richness and abundance, the estimates of mean species richness and abundance, the corresponding estimates of standard deviations, and sample sizes were tabulated. If the estimate of standard deviation was not provided it was calculated from

Table 2. Hierarchy of quality of evidence based on the information provided in the documents.

\begin{tabular}{cl}
\hline Category & Quality of evidence presented \\
\hline I. & Randomized controlled trials of adequate spatial and temporal scale for the study species. \\
II. & Controlled trials without randomization with adequate spatial and temporal scale for the study species. \\
III. & Comparisons of differences between sites with and without controls with adequate spatial and \\
IV. & Evidence obtained from multiple time series or from dramatic results in uncontrolled experiments. \\
V. & Opinions of respected authorities based on qualitative field evidence, descriptive studies or reports of \\
VI. & Expert committees.
\end{tabular}


the estimate of standard error and sample size. In some cases the estimates of mean and standard deviation or standard error were measured from the published figures. The measurements were made by one person, so any measurement error is expected to be consistent. In cases where the estimates of mean and standard deviation were not provided but a $t$-statistic was, this was used to calculate Hedges' $d$ by transforming the $t$-statistic first to Hedges' $g$ and then the $g$ to Hedges' $d$ (Rosenberg et al. 1999).

The effect sizes were analyzed using a random effects model. This was chosen because the subject groups and data collection methods varied between the studies, and hence there may be real differences among effect sizes of studies on different subjects (Cooper et al. 2009; Borenstein et al. 2011). Different taxa and taxa that were collected using different methods within the same study were treated as independent samples. Also, data that had significant differences between sampling occasions (Chung et al. 2000; Davis and Philips 2005) were included as independent samples. Studies by different authors from the same location, regardless of the taxa studied, were treated as separate cases. Although originally we wanted to include explanatory variables into the model, this was not feasible owing to the small number of studies that met the inclusion criteria, and hence only the average effect sizes were estimated, along with 95\% bias-corrected confidence intervals. The biascorrected confidence intervals were chosen because of the relatively small sample sizes. The analyses were performed using MetaWin 2.1 release 5.10 (Rosenberg et al. 1999).

One of the well-known problems associated with meta-analysis is that studies with higher effects are more likely to be published; relying only on results published in academic journals can potentially lead to misleading conclusions about the effect (Borenstein et al. 2011). To address this problem, an extensive search was performed to uncover "grey" (variously defined, but here we mean conference papers, book chapters, reports that are not part of established Series, etc.) and unpublished literature. Another reported source of publication bias is that non-significant results may not be published at all. We did not test for publication bias for two reasons. First, a variety of responses are expected in ecological studies dealing with different taxa and we therefore did not expect suppression by editors of studies of smaller effects or non-significant results. Secondly, existing statistical tests require reasonable numbers of cases and dispersion in sample sizes, two conditions which the meta-analyses we performed do not fully meet.

A variety of different methods used for examining changes in species composition makes it difficult, quantitatively, to assess the effects of habitat modification on species composition. Hence, to have a standardized measure to assess changes in species composition, a simple averaging method following Nichols et al. (2007) was used to calculate the mean change in the number of shared species between forest and oil palm habitats, standardized by the total number of species recorded in forest. In addition to the mean response, $95 \%$ confidence intervals were calculated. The value was considered significant when the confidence interval did not include one. Primary and secondary forest data were combined in the analysis. When both primary and secondary forests were sampled, only primary forest data were used. The analysis was performed using SPSS version 17.0 (SPSS Statistics for Windows, Version 17.0. 2008). 


\section{Results}

\subsection{Review statistics}

The searches returned 9143 articles after duplicate removal (Figure 1). Of these articles, approximately 13 per cent had a relevant title and keywords and were therefore examined further. At the abstract-assessment stage, 9.8 per cent of articles satisfied the inclusion criteria and were read in full. Of those, 25 articles ( 21 per cent of those read in full) reported single studies with an appropriate comparator (Appendix 3). All of the selected studies belonged to category III (Table 2), which meant that none were excluded on the grounds of weak methodology.

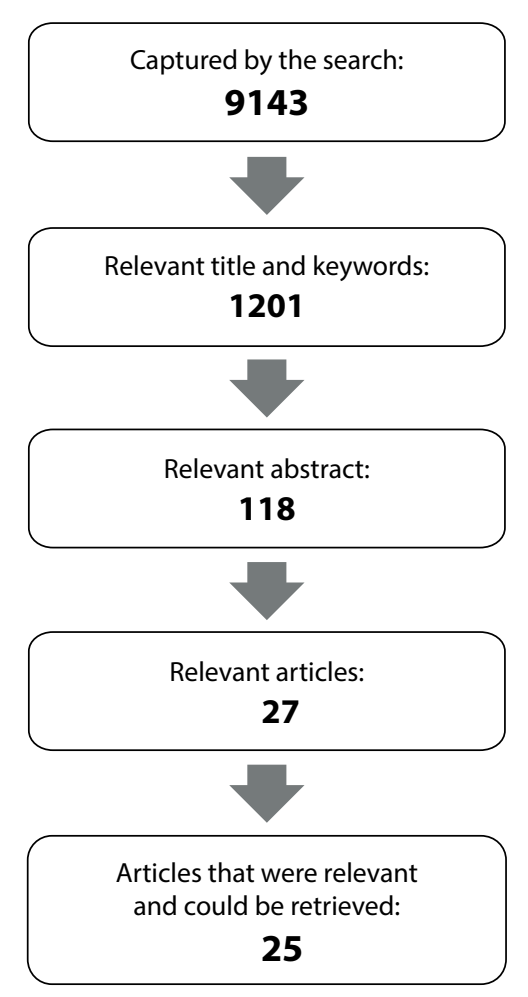

Figure 1. The number of articles at different assessment stages.

\subsection{Description of studies}

\subsubsection{Source}

All 25 articles included in the review were published in peer-reviewed journals. Only three articles were published before 2000, and the majority of the articles were published after 2005 (Figure 2). The figure for 2012 is not fully representative of the whole year because the search was conducted on articles published by the bibliographic databases up to November 2012.

\subsubsection{Context of the studies}

\section{Study location}

Most of the studies were conducted in Asia: 20 of them in Malaysia. Of the studies conducted in Malaysia, 10 were from one state; Sabah. There were only single studies from other tropical regions, Africa (Ghana), Oceania (Papua New Guinea), and Latin America (Dominican Republic).

\section{Study comparator}

Only studies of oil palm were retrieved using our search strategy. Typically, oil palm plantations were compared with forest, either primary $(n=20)$ or secondary forest $(n=14)$. All except one study were site comparisons. None of the studies were experimental. Only one of the studies examined outcomes before and after forest conversion.

\section{Study outcomes}

The 25 studies reported a total of 58 outcomes. All studies had examined faunal species richness/ diversity $(n=25)$; almost all had examined abundance $(n=21)$, but only 12 had looked at species composition. Almost two thirds of them studied invertebrates (Figure 3). 


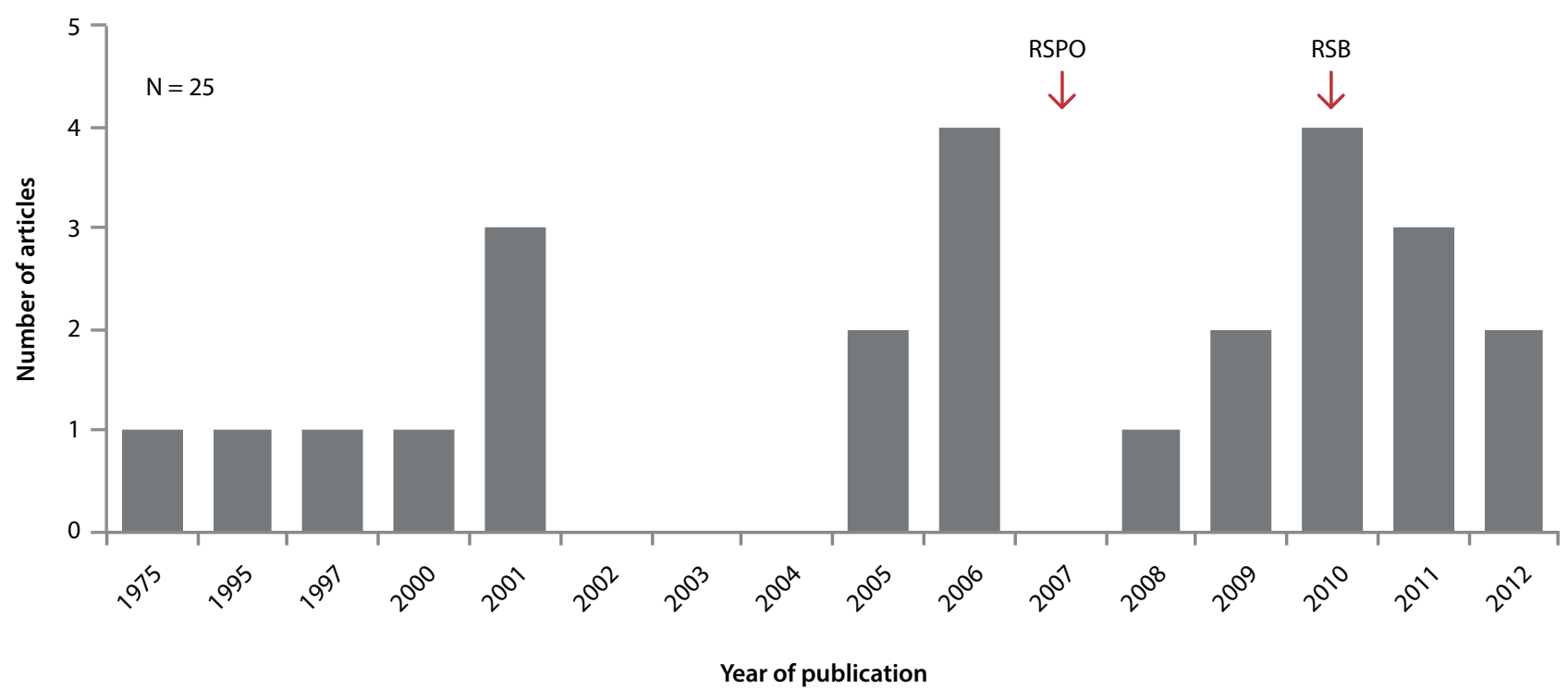

Figure 2. Number of articles published in different years. The articles shown are limited to those included in this systematic review. For articles published before 2000 only those years in which an article was published are shown. Arrows indicate the years when standards from Roundtable on Sustainable Palm Oil (RSPO) and Roundtable on Sustainable Biofuels (RSB) were first published.

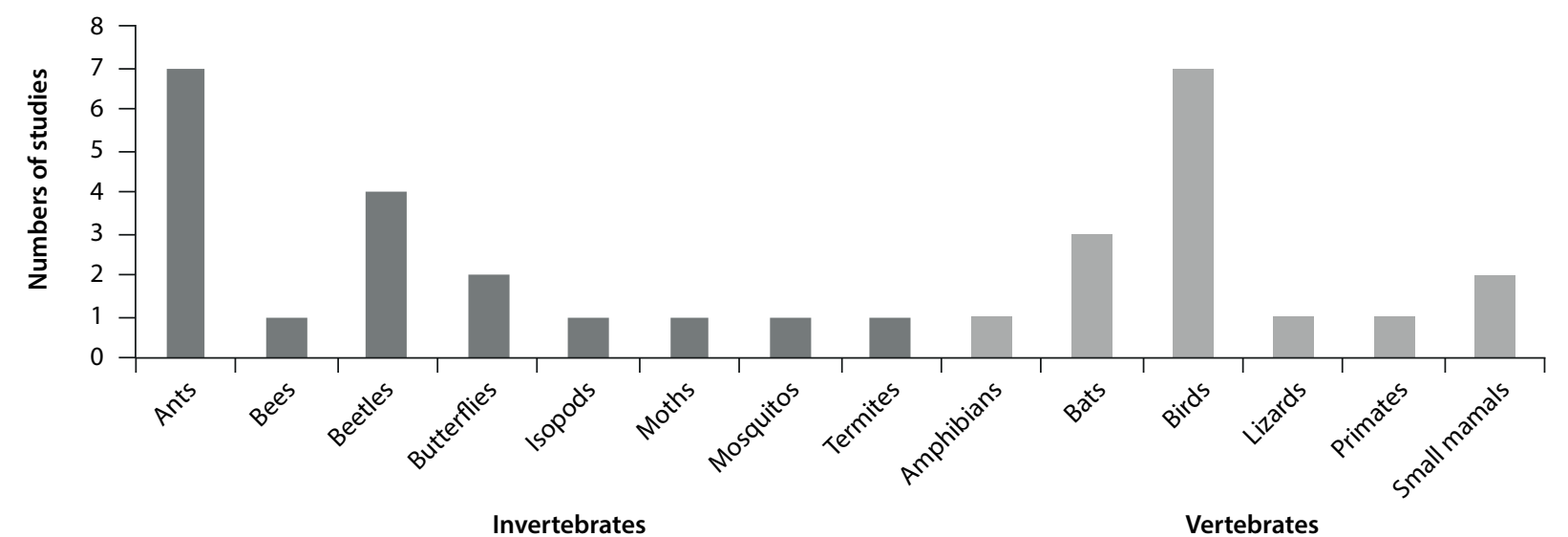

Figure 3. Taxonomic groups studied in the $\mathbf{2 5}$ studies on biodiversity included in the review. Some of the studies looked at several taxonomic groups.

\section{The age and size of the plantations}

The age of the plantations was reported in 15 studies; two additional studies mentioned that the plantation was 'mature'. The age of the plantations varied from one year to more than 25 years. Nine studies collected data from plantations aged less than ten years, eight studies collected data from plantations aged ten years or more, including the study by Azhar et al. (2011) that collected data from oil palm plantations of varying ages. Only ten studies mentioned plantation area, which ranged from 36 to 16,000 hectares, with the majority of studies having studied plantations of several thousand hectares (Figure 4). 


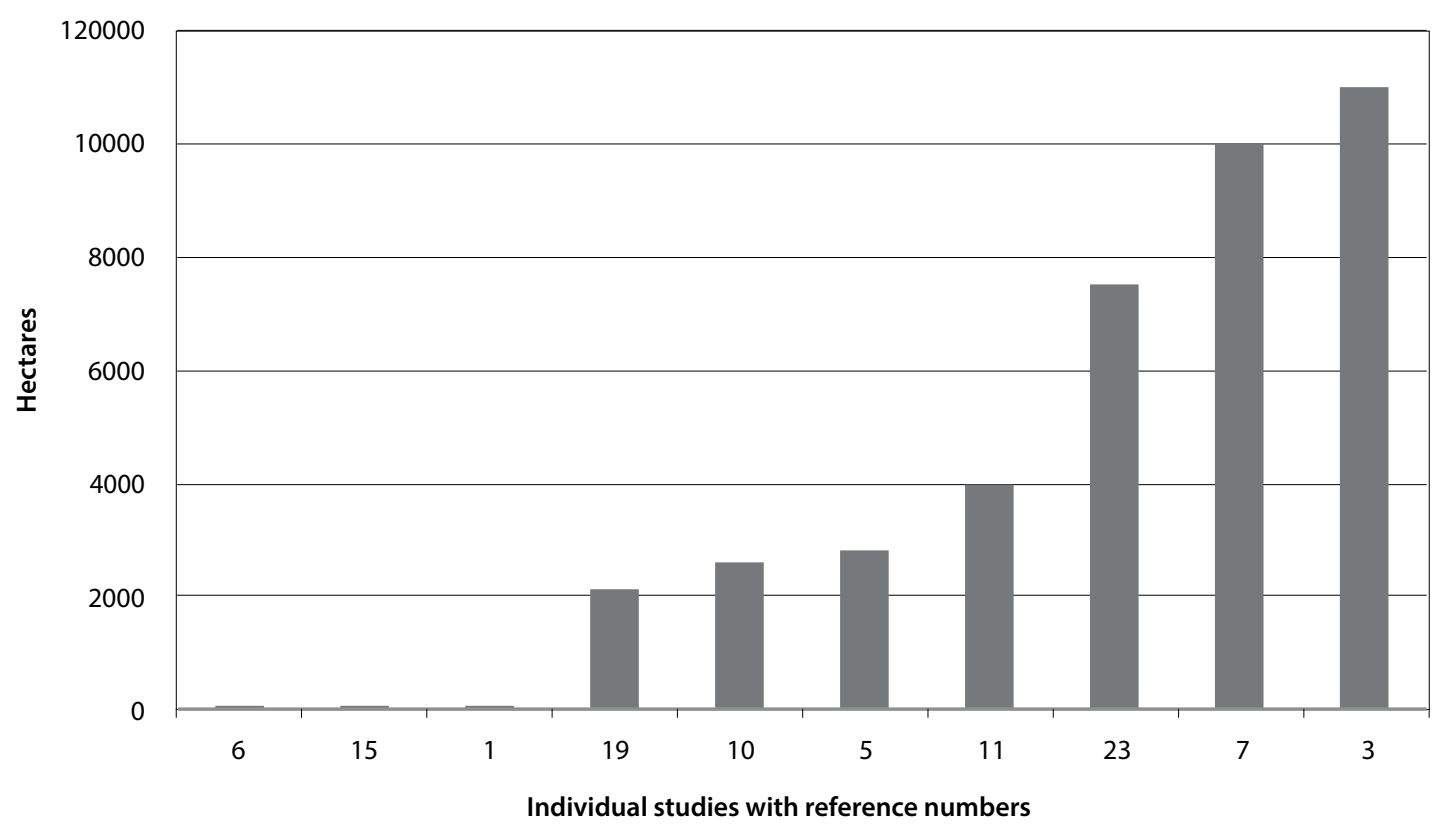

Figure 4. The size of plantations studied. The bars represent individual studies and the labels refer to the study numbers in Appendix 3.

\subsubsection{Study designs and methodology}

All studies included in the review used quantitative methods. All except one study were site comparisons between oil palm plantation and primary or secondary forest or both. In the one before-and-after study, Chang et al. (1997) studied changes in abundance of mosquitoes induced by land use change during the development of an oil palm plantation.

All site comparison studies selected sites that could be paired and, except for Koh and Wilcove (2008), collected data from the sites during the same time period. Koh and Wilcove (2008) used butterfly data collected from primary and logged forest in two earlier studies (Hamer et al. 2003, and Dumbrell and Hill 2005) and compared it with the data they collected from an oil palm plantation. The exact method for site selection or pairing was described in only four studies (Chey 2006, Azhar et al. 2011, Vaessen et al. 2011, and Lucey and Hill 2012). It was impossible to assess the robustness of the selection in the other studies. Similarly, the selection of sub-sites within the studied habitats was unclear in most of the studies as even the studies that selected sub-sites randomly did not explain the exact method for randomization.
Half of the studies reported distance between the sites and only ten studies discussed leakage effects from or to adjacent areas. One of these (Lucey and Hill 2012) was specifically focused on spillover of butterflies and ants from forest to oil palm plantations and found that although vagrant forest butterflies were found in the plantations, recapture data did not reveal dispersal of butterflies across the forest-plantation ecotone. No spillover of ant species was reported. In addition, it was reported that leakage from adjacent areas was unlikely, owing to behavioral characteristics (Bernard et al. 2009), to dispersal capabilities (Chang et al. 1997, and Hassall et al. 2006), or ecological conditions (Brühl and Eltz 2010). In three studies on birds it was reported that nearby primary forest areas either "probably" (Sheldon et al. 2010) or "certainly" (Peh et al. 2006, and Azhar et al. 2011) contributed to the species richness in oil palm landscapes. Similarly, Gillespie et al. (2012) suggested that it is possible that the occurrence of arboreal amphibian species (tree frogs), specifically Rhacophorus appendiculatus, Rhacophorus dulitensis and Rhacophorus pardalis, in the plantation resulted from local dispersal from nearby forest habitats. Shafie et al. (2011) suspected that the lack of shelter or roosting sites in areas adjacent to the oil palm plantation studied could have contributed to the high abundance of bats in the plantation. 


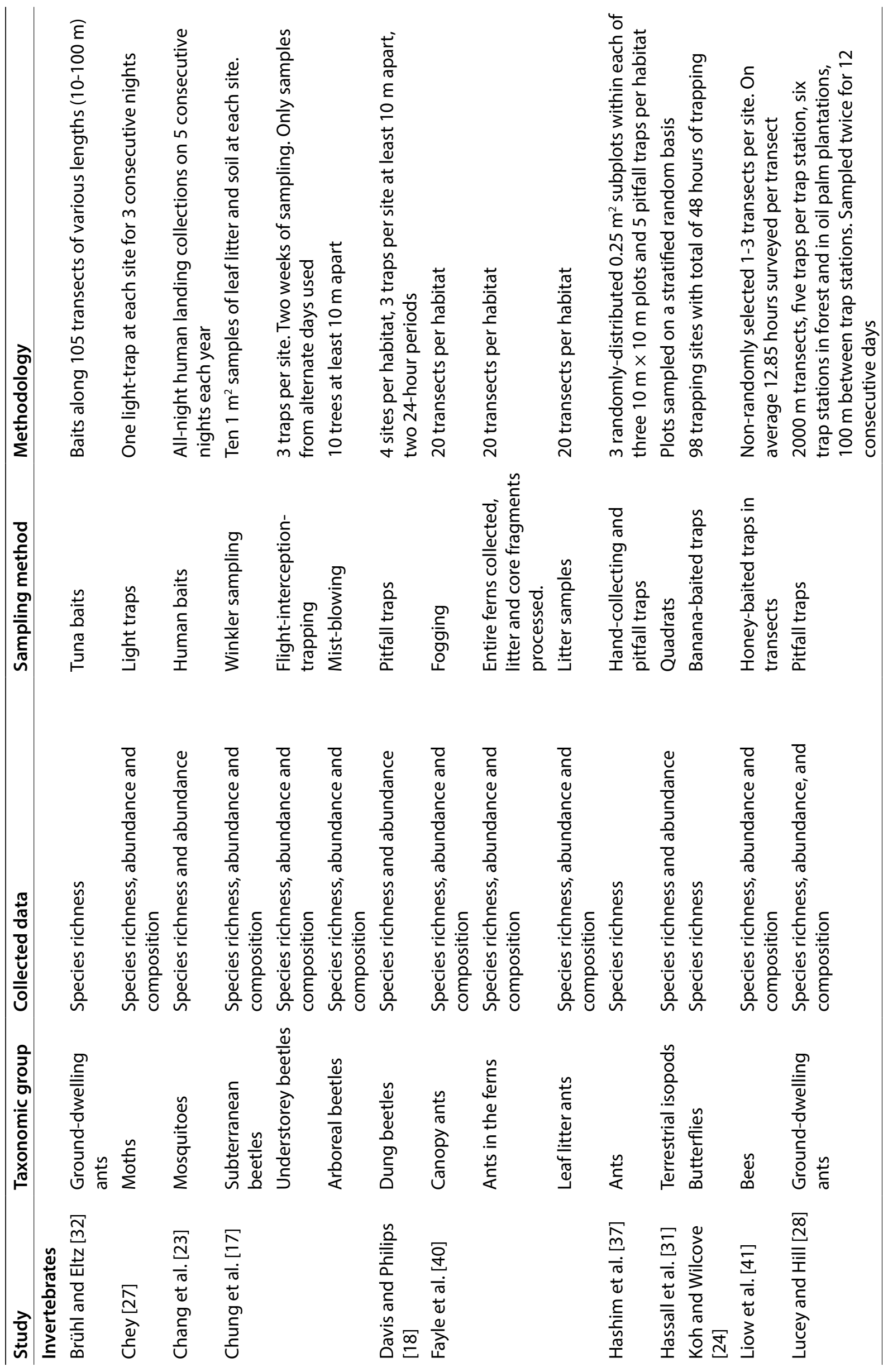




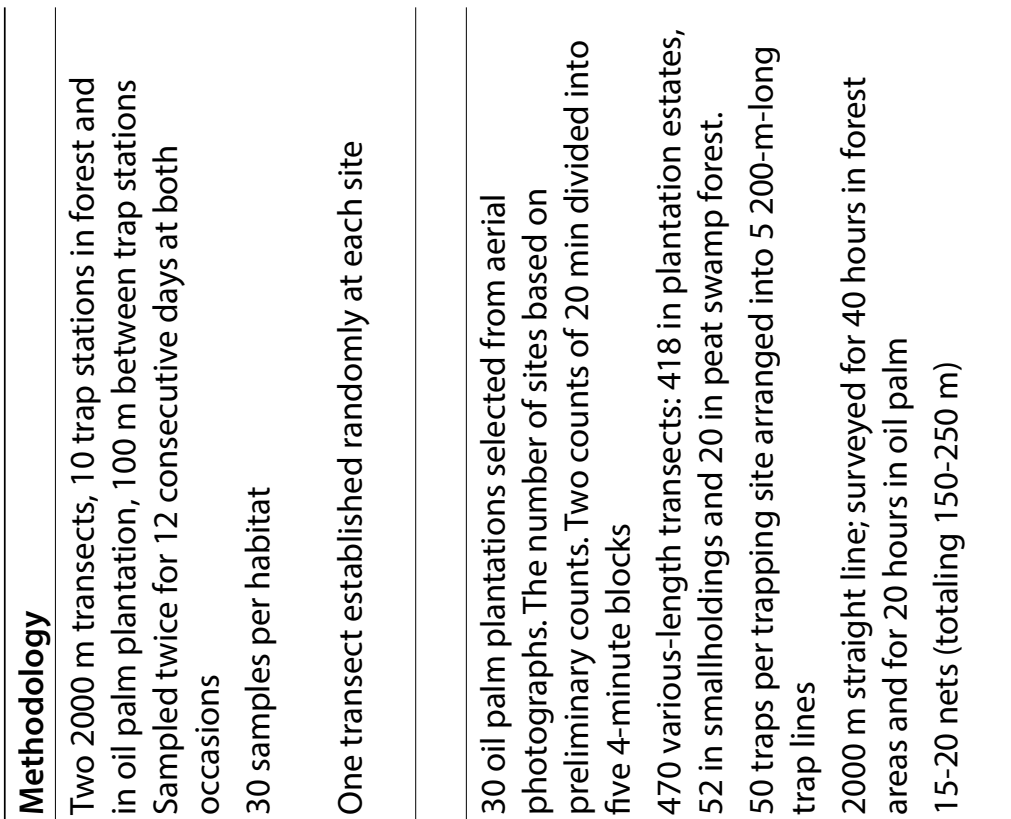

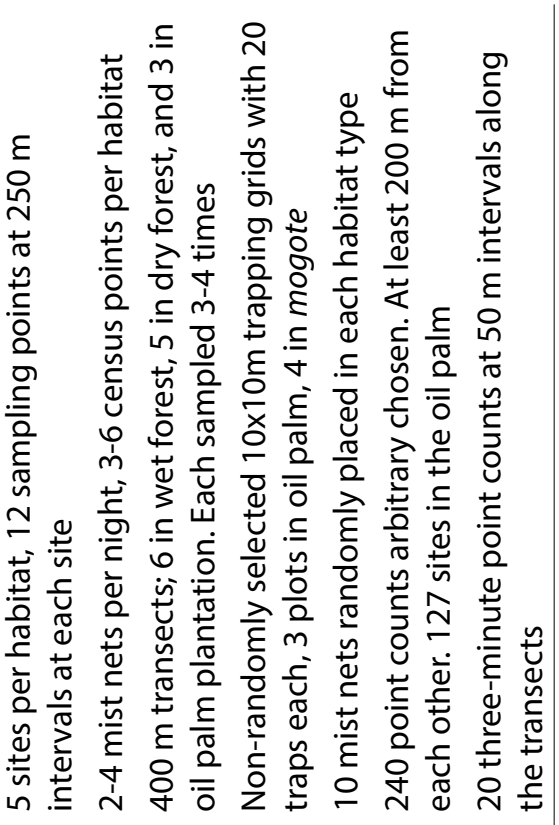

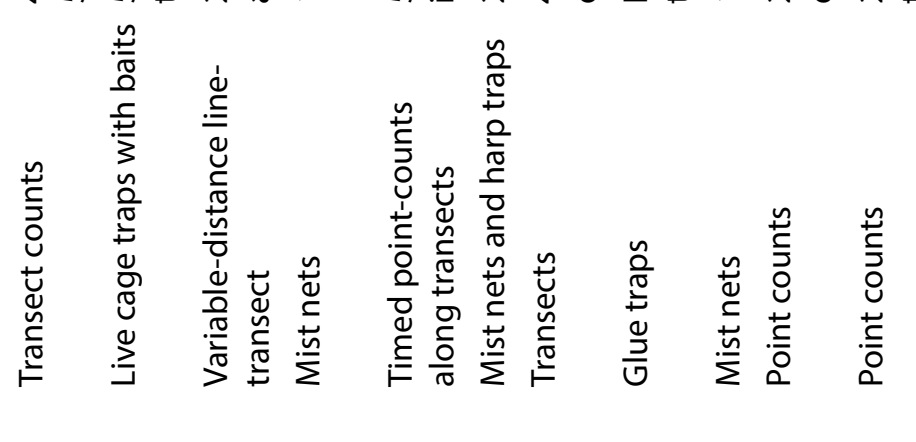

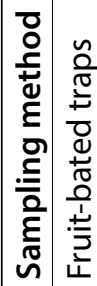

$\stackrel{n}{5}$

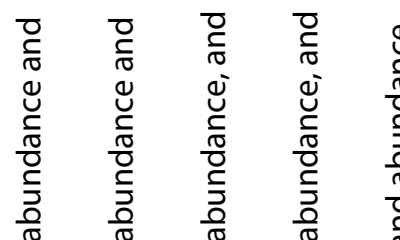

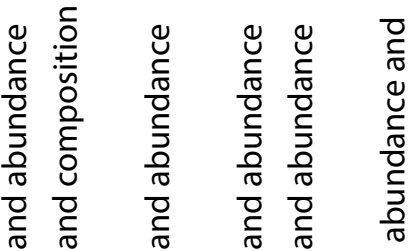

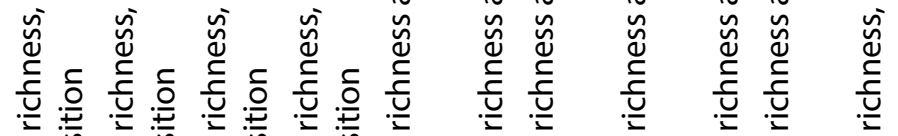

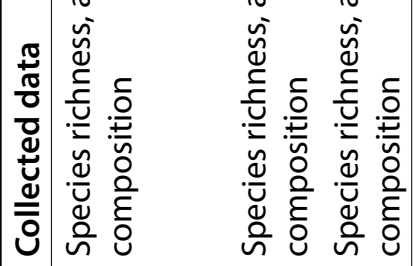

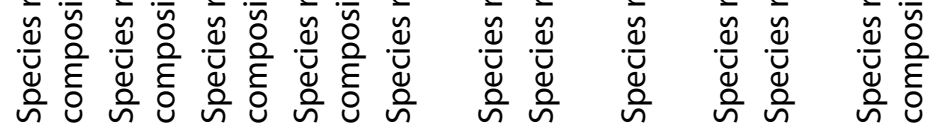

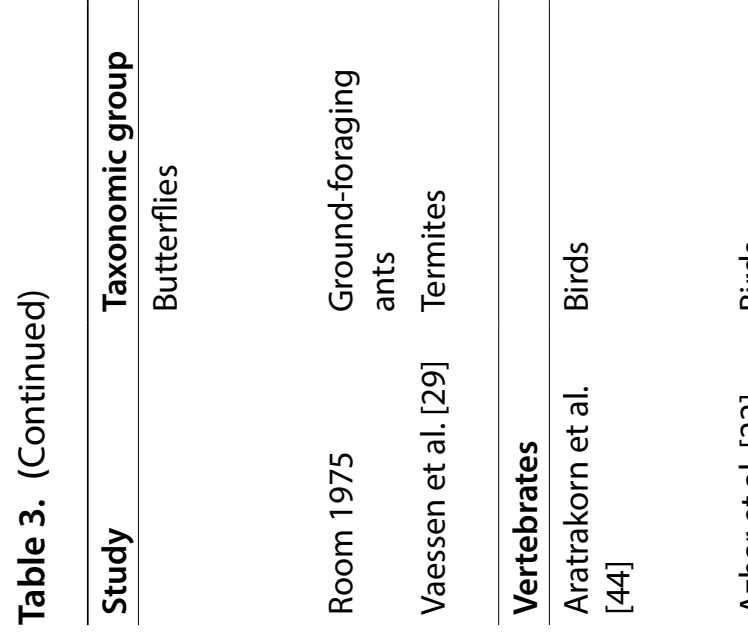

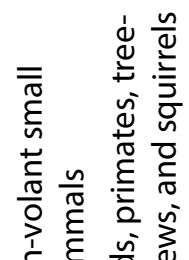

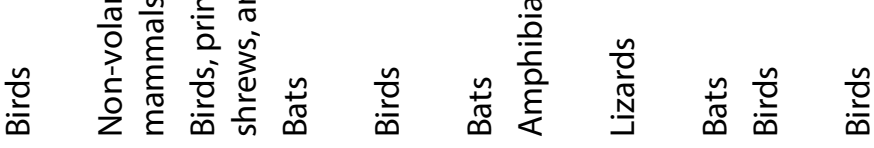

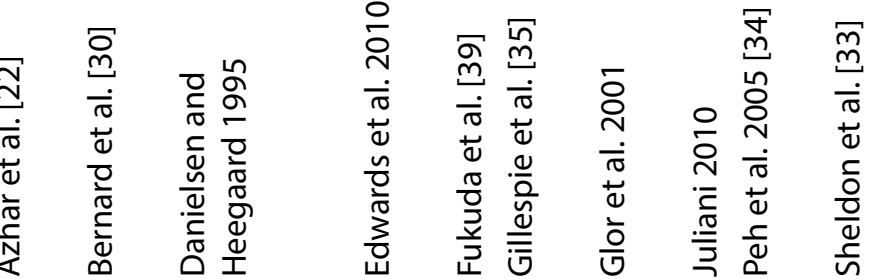


The species studied in the faunal studies varied considerably, and therefore the data collection methods also differed (Table 3). Sampling effort was statistically evaluated in almost two thirds of the studies $(58 \%)$ and in addition one more study (Hashim et al. 2009) reported that it was 'low'. The most frequently reported method of evaluating sampling effort was by use of species accumulation curves; comparisons between observed and predicted species richness were used in three studies (Davis and Philips 2005, Brühl and Eltz 2010, and Azhar et al. 2011). Generally, the studies that had statistically evaluated the sampling effort deemed it to be satisfactory to show the differences (or lack of differences) between the sites, and 11 of the 14 studies specifically discussed that point.

Nine of the studies explicitly reported efforts aimed at minimizing or controlling for the effect of extrinsic variables. For example, sampling at the same time of day, or only in fine weather conditions, collecting samples away from the edges of the habitat, and sampling birds at a limited spatial scale to ensure visibility.

\subsubsection{Temporal and spatial scale of the studies}

Temporal and spatial scales are important in several contexts. Although the spatial scale of data collection can influence the results of faunal studies (Hamer and Hill 2000), this was rarely discussed in the studies. Only two studies (Hassall et al. 2006, and Lucey and Hill 2012) discussed the results in the context of spatial scale, specifically in relation to the dispersal abilities of the species in question.

None of the studies collected long-term data, and hence the studies are based on a rather limited time scale. In addition, only two studies assessed the effects of seasonality. Fukuda et al. (2009) conducted censuses on bats four times within 17 months and did not detect any significant differences between the seasons. Lucey and Hill (2012) compared similarity of species assemblages between first and second sampling occasion and concluded that for butterfly species temporal turnover contributed substantially to overall diversity. For ant species the similarity of species assemblages was higher for both forest and oil palm habitats, and thus, temporal turnover had less impact on the diversity of ants than butterflies.

\subsection{Quantitative synthesis}

\subsubsection{Species richness}

We found 11 studies that provided suitable data for conducting meta-analysis to compare species richness in oil palm plantations and primary forest, and 8 whose data could be used for comparison between oil palm plantations and secondary forests. Owing to the limited amount of suitable data we focused on overall effects. Although examining only overall effects can mask differences in responses between taxa, it was done out of necessity to retain power in the analyses. As primary and secondary forests can be biologically very different environments, the analyses were done separately.

There was relatively uniform negative response as shown in the forest plots of differences in species richness between oil palm plantation and either primary or secondary forest (Figures 5 and 6). The estimated mean effect size was significantly different from zero (primary forest: $\mathrm{E}_{++}=-1.41$, 95\% bias-corrected CI -2.06 to -0.90 ; secondary forest: $\mathrm{E}_{++}=-3.02,95 \%$ bias-corrected CI -4.42 to -1.84$)$ indicating that oil palm plantations have fewer species than either primary or secondary forest. As the effect sizes got larger, the confidence intervals were also wider.

There was heterogeneity in the effects when the species richness of plantation was compared to that of primary forest $(Q=29.76, p=0.02)$, but not when the comparison was between plantation and secondary forest $(Q=16.19, p=0.24)$.

The $I^{2}$ index indicated that $43 \%$ of the variance considering the effects regarding plantations and primary forests reflects real differences in the effect sizes. Correlations between effect and sample sizes were not significant (Spearman's rank correlation, $p>0.05$ ) for either primary or secondary forest implying that larger effects in one direction were not reported more often than other effects, but at low sample sizes the power of the correlation is rather low (Borenstein et al. 2011). 


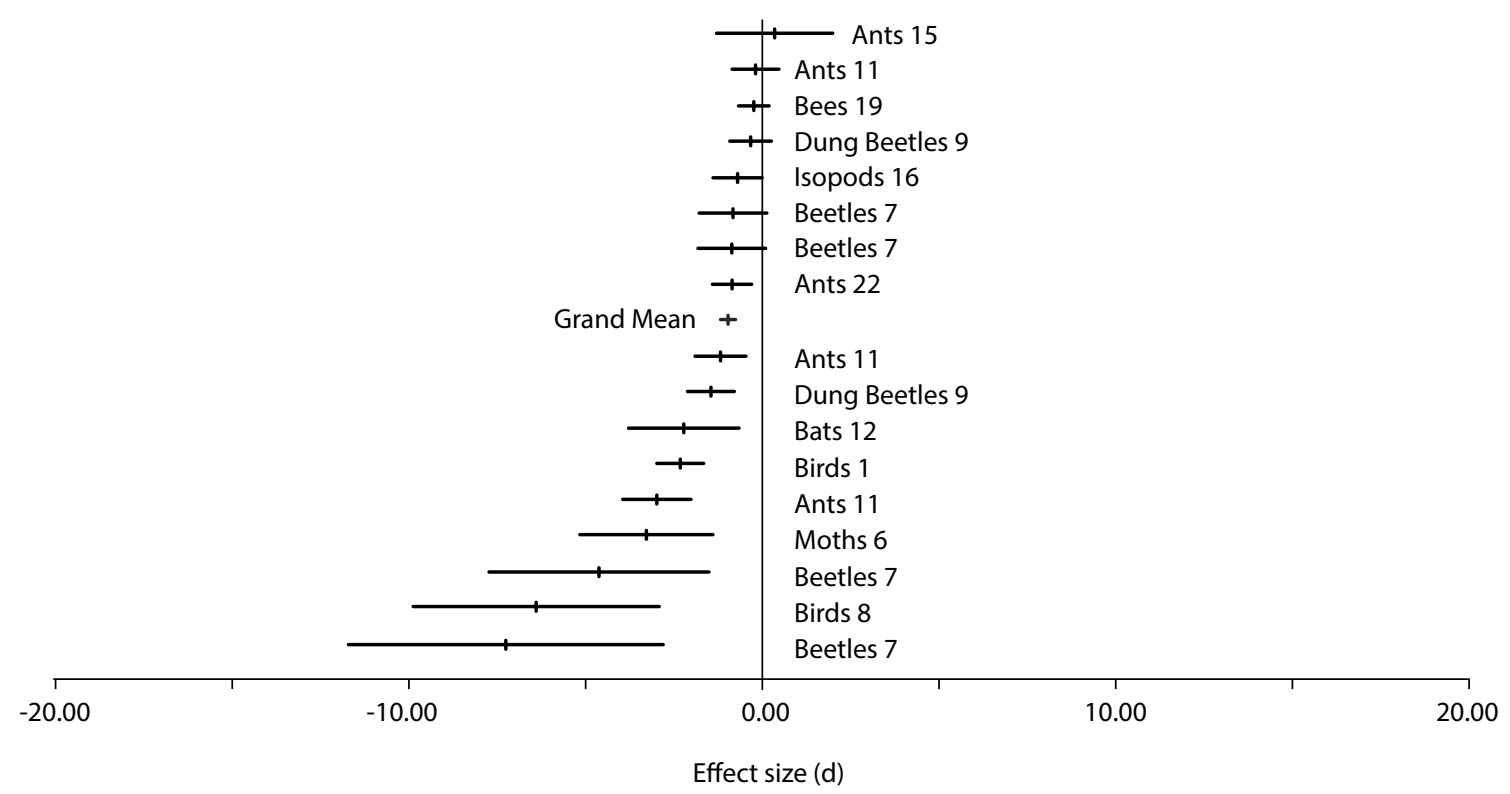

Figure 5. Forest plot of effect sizes for species richness (mean standardized difference between primary forest and oil palm plantation). The grand mean is the summary effect of all the individual effect sizes. The error bars represent $95 \%$ confidence intervals. The numbers after the taxa refer to the study number in Appendix 3.

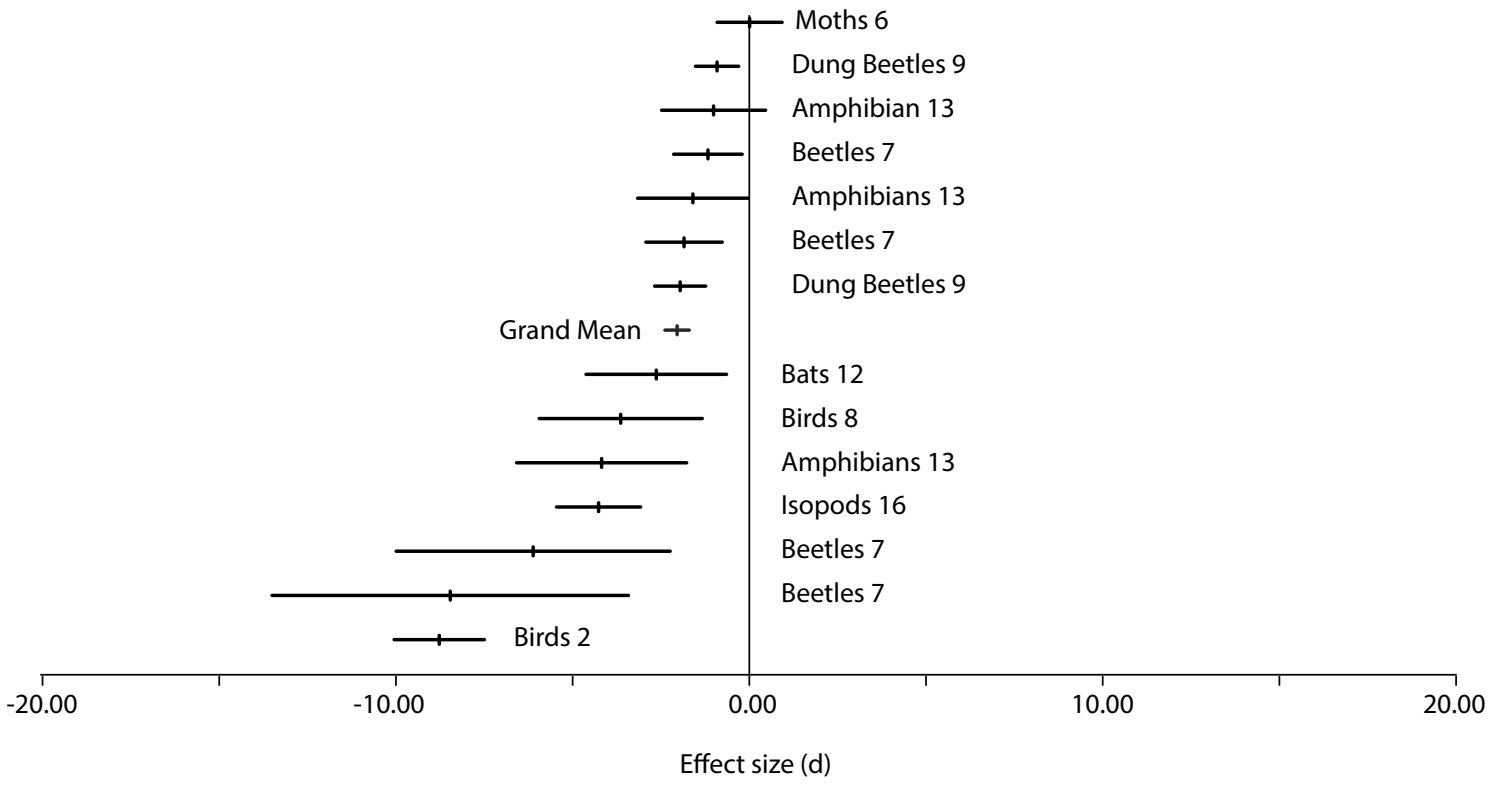

Figure 6. Forest plot of effect sizes for species richness (mean standardized difference between secondary forest and oil palm plantation). The grand mean is the summary effect of all the individual effect sizes. The error bars represent $95 \%$ confidence intervals. The numbers after the taxa refer to the study number in Appendix 3. 


\subsubsection{Abundance}

There was more dispersion in the direction of effect sizes of abundances (i.e. the overall number of individuals or occurrences) than of species richness, and the mean effect size was not significantly different from zero for the comparison of an oil palm plantation to either primary forest $\left(\mathrm{E}_{++}=-0.92,95 \%\right.$ bias-corrected CI -2.03 to
0.01) (Figure 7) or secondary forest $(\mathrm{E}++=$ $-0.21,95 \%$ bias-corrected CI -1.58 to 0.75 ) (Figure 8). However, it is important to note that the results for the secondary forests were based on only four independent studies, and that owing to the limitations in data available, we aggregated all taxa in these analyses. As with species richness, larger effect sizes had larger confidence intervals.

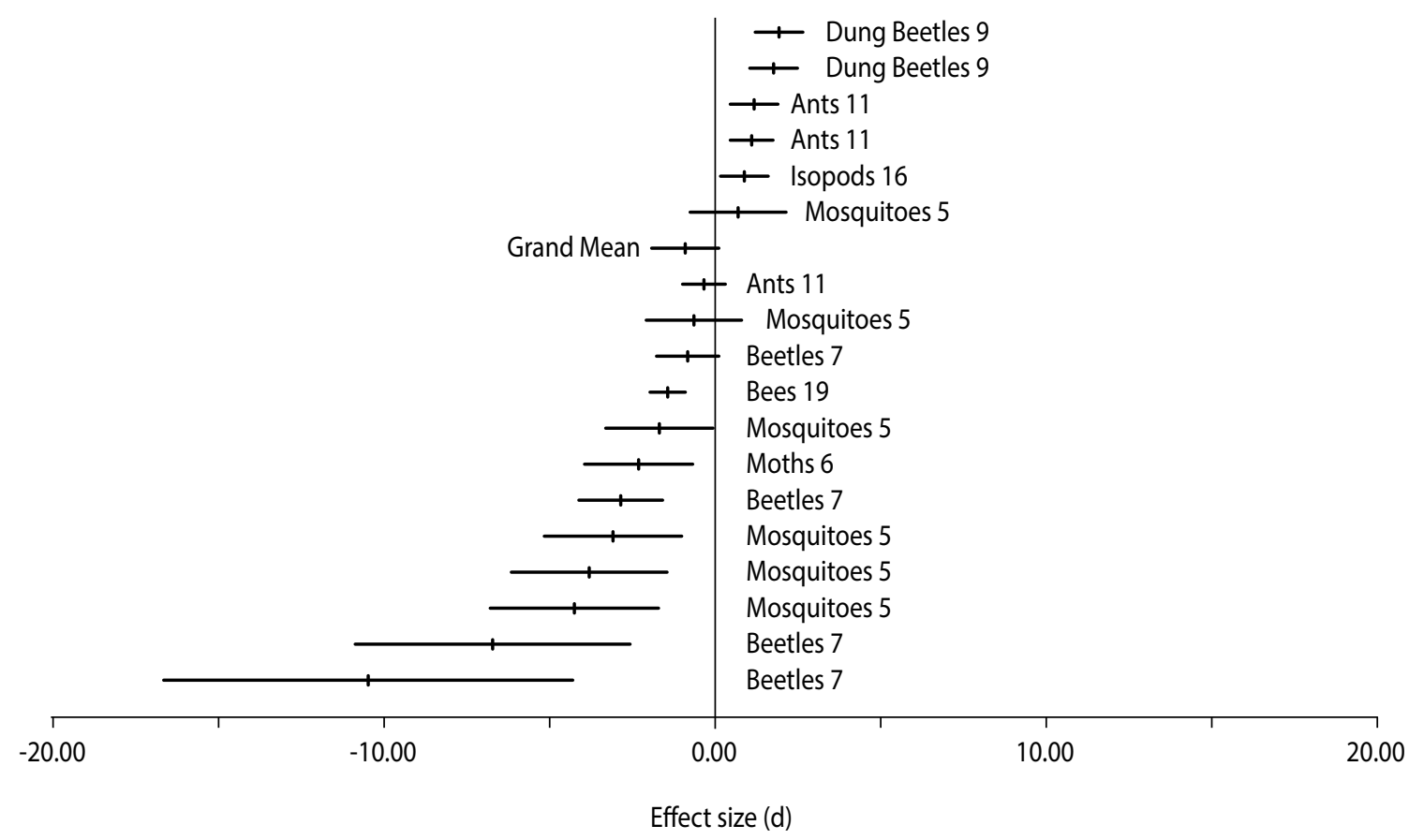

Figure 7. Forest plot of effect sizes for abundance of individuals (mean standardized difference between primary forest and oil palm plantation). The grand mean is the summary effect of all the individual effect sizes. The error bars represent $95 \%$ confidence intervals. The numbers after the taxa refer to the study number in Appendix 3.

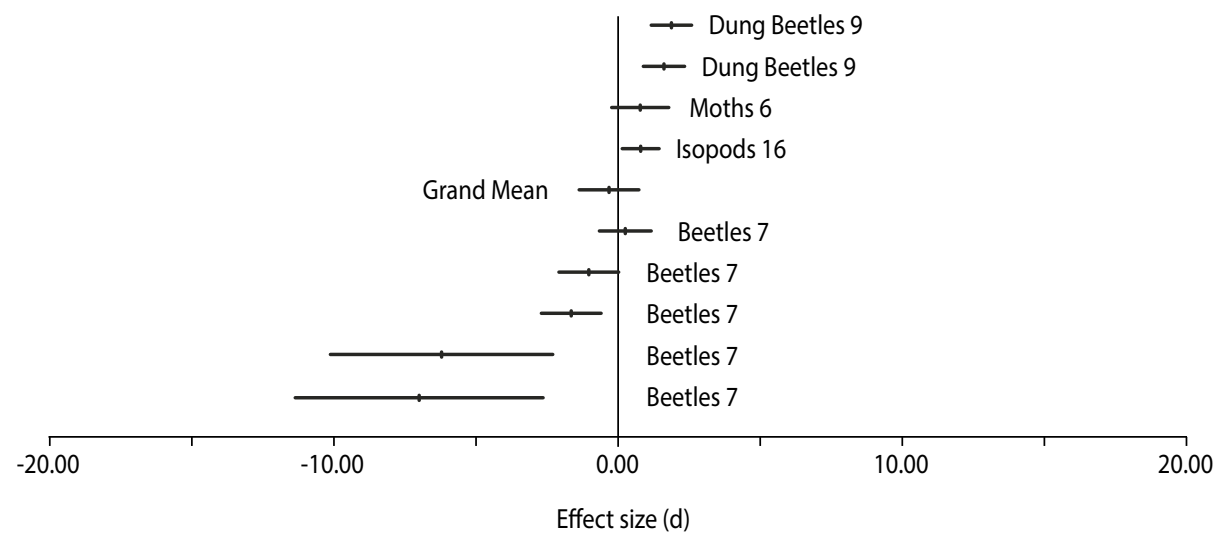

Figure 8. Forest plot of effect sizes for abundance of individuals (mean standardized difference between secondary forest and oil palm plantation). The grand mean is the summary effect of all the individual effect sizes. The error bars represent $95 \%$ confidence intervals. The numbers after the taxa refer to the study number in Appendix 3. 
There was heterogeneity in the effect sizes when the abundance of plantations was compared with primary forest $(Q=31.88, p=0.02)$ as well as with a secondary forest $(Q=19.35, p=0.01)$. The $I^{2}$ index indicated that $47 \%$ of the variance considering the effects regarding plantations and primary forests reflects real differences in the effect sizes. The figure was 59\% when faunal abundance of secondary forests and plantations were compared. Correlations between effect and sample sizes were not significant for either primary or secondary forest (Spearman's rank correlation, $p>0.05)$.

\subsubsection{Species composition}

The similarity of species composition was statistically assessed in 12 of the original studies while a further 11 studies provided some information about species composition (Tables 4 and 5). Species composition differed between forest and oil palm plantation areas in all except one of the 23 studies. In most of the studies that had statistically assessed the difference, the similarity between plantation and forest areas was either low or zero. However, the statistical methods used differed between the studies and results are therefore not directly comparable.

Table 4. Summary of information on species composition provided in the reviewed studies.*

\begin{tabular}{|c|c|c|c|c|c|c|}
\hline Authors & $\begin{array}{c}\text { Year } \\
\text { published }\end{array}$ & Taxonomic group & $\begin{array}{l}\text { Forest } \\
\text { species }\end{array}$ & $\begin{array}{c}\text { Plantation } \\
\text { species }\end{array}$ & $\begin{array}{c}\text { Number of } \\
\text { shared species }\end{array}$ & $\begin{array}{c}\text { Proportion of } \\
\text { species remaining }\end{array}$ \\
\hline \multicolumn{7}{|l|}{ Invertebrates } \\
\hline Brühl & 2001 & Ground-dwelling ants & 31 & 23 & 14 & 0.45 \\
\hline Chang et al. & 1997 & Mosquitoes & 6 & 6 & 6 & 1.00 \\
\hline Chey & 2006 & Moths & 75 & 85 & 28 & 0.37 \\
\hline Chey & 2006 & Moths & 133 & 73 & 28 & 0.21 \\
\hline Chey & 2006 & Moths & 78 & 90 & 11 & 0.14 \\
\hline Davis and Philips & 2005 & Dung beetles & 25 & 20 & 8 & 0.32 \\
\hline Fayle et al. & 2010 & Ants (canopy) & 120 & 58 & 17 & 0.14 \\
\hline Fayle et al. & 2010 & Ants (ferns) & 36 & 35 & 2 & 0.06 \\
\hline Fayle et al. & 2010 & Ants (leaf-litter) & 216 & 56 & 29 & 0.13 \\
\hline Hashim et al. & 2010 & Ants & 5 & 7 & 3 & 0.60 \\
\hline Hassall et al. & 2006 & Terrestrial isopods & 12 & 4 & 0 & 0.00 \\
\hline Koh and Wilcove & 2008 & Butterflies & 69 & 15 & 12 & 0.17 \\
\hline Room & 1975 & Ground-foraging ants & 49 & 29 & 11 & 0.22 \\
\hline Vaessen et al. & 2011 & Termites & 11 & 6 & 2 & 0.18 \\
\hline Mean & & & & & & 0.29 \\
\hline SD & & & & & & 0.26 \\
\hline n & & & & & & 14 \\
\hline $95 \% \mathrm{Cl}$ & & & & & & 0.14 \\
\hline \multicolumn{7}{|l|}{ Vertebrates } \\
\hline Aratrakorn et al. & 2006 & Birds & 108 & 41 & 21 & 0.19 \\
\hline Bernard et al. & 2009 & $\begin{array}{l}\text { Non-volant small } \\
\text { mammals }\end{array}$ & 6 & 1 & 0 & 0.00 \\
\hline Danielsen and Heegaard & 1995 & Primates & 5 & 1 & 0 & 0.00 \\
\hline Danielsen and Heegaard & 1995 & Bats & 8 & 1 & 1 & 0.13 \\
\hline Fukuda et al. & 2009 & Bats & 19 & 5 & 4 & 0.21 \\
\hline Gillespie et al. & 2012 & Amphibians & 21 & 12 & 10 & 0.48 \\
\hline Glor et al. & 2001 & Lizards & 11 & 5 & 4 & 0.36 \\
\hline Juliani & 2010 & Bats & 9 & 7 & 3 & 0.33 \\
\hline Peh et al. & 2005,2006 & Birds & 159 & 40 & 36 & 0.23 \\
\hline Azhar et al. & 2011 & Birds & 194 & 55 & 49 & 0.25 \\
\hline Mean & & & & & & 0.22 \\
\hline SD & & & & & & 0.15 \\
\hline $\mathrm{n}$ & & & & & & 10 \\
\hline $95 \% \mathrm{Cl}$ & & & & & & 0.09 \\
\hline
\end{tabular}

*The causes marked in bold were statistically significant. 


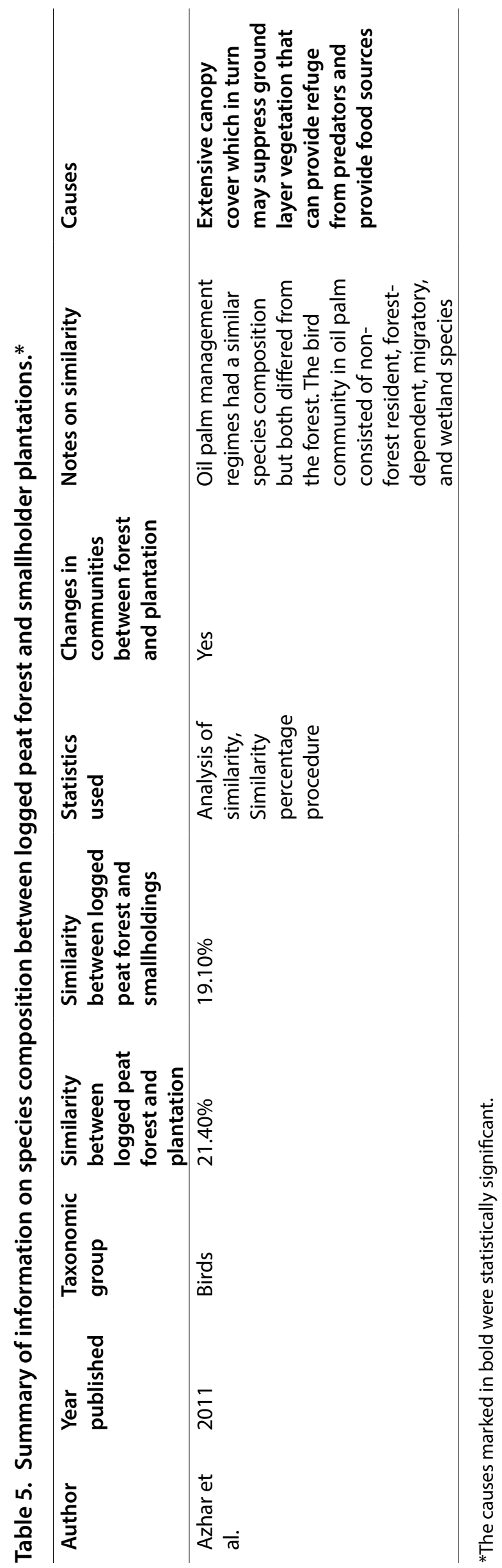


To have comparable results, a mean of shared species between oil palm plantation and forest was assessed. There were 10 studies on invertebrates and 9 studies on vertebrates that provided suitable data for the comparison. On average only $29 \%$ of the invertebrate species and $22 \%$ of the vertebrate species were shared between oil palm plantation and forest after the values were standardized (Table 6, Figure 9). This represents significant change in community composition for both invertebrates and vertebrates.

Table 6. Total species richness in forests and plantations, the number of shared species, and the proportion of species remaining.

\begin{tabular}{|c|c|c|c|c|c|c|}
\hline Authors & $\begin{array}{c}\text { Year } \\
\text { published }\end{array}$ & $\begin{array}{l}\text { Taxonomic } \\
\text { group }\end{array}$ & $\begin{array}{l}\text { Forest } \\
\text { species }\end{array}$ & $\begin{array}{l}\text { Plantation } \\
\text { species }\end{array}$ & $\begin{array}{c}\text { Number of } \\
\text { shared species }\end{array}$ & $\begin{array}{c}\text { Proportion of } \\
\text { species remaining }\end{array}$ \\
\hline \multicolumn{7}{|l|}{ Invertebrates } \\
\hline Brühl & 2001 & $\begin{array}{l}\text { Ground- } \\
\text { dwelling ants }\end{array}$ & 31 & 23 & 14 & 0.45 \\
\hline Chang et al. & 1997 & Mosquitoes & 6 & 6 & 6 & 1.00 \\
\hline Chey & 2006 & Moths & 75 & 85 & 28 & 0.37 \\
\hline Chey & 2006 & Moths & 133 & 73 & 28 & 0.21 \\
\hline Chey & 2006 & Moths & 78 & 90 & 11 & 0.14 \\
\hline Davis and Philips & 2005 & Dung beetles & 25 & 20 & 8 & 0.32 \\
\hline Fayle et al. & 2010 & Ants (canopy) & 120 & 58 & 17 & 0.14 \\
\hline Fayle et al. & 2010 & Ants (ferns) & 36 & 35 & 2 & 0.06 \\
\hline Fayle et al. & 2010 & $\begin{array}{l}\text { Ants (leaf- } \\
\text { litter) }\end{array}$ & 216 & 56 & 29 & 0.13 \\
\hline Hashim et al. & 2010 & Ants & 5 & 7 & 3 & 0.60 \\
\hline Hassall et al. & 2006 & $\begin{array}{l}\text { Terrestrial } \\
\text { isopods }\end{array}$ & 12 & 4 & 0 & 0.00 \\
\hline Koh and Wilcove & 2008 & Butterflies & 69 & 15 & 12 & 0.17 \\
\hline Room & 1975 & $\begin{array}{l}\text { Ground- } \\
\text { foraging ants }\end{array}$ & 49 & 29 & 11 & 0.22 \\
\hline Vaessen et al. & 2011 & Termites & 11 & 6 & 2 & 0.18 \\
\hline Mean & & & & & & 0.29 \\
\hline SD & & & & & & 0.26 \\
\hline $\mathbf{n}$ & & & & & & 14 \\
\hline $95 \% \mathrm{Cl}$ & & & & & & 0.14 \\
\hline \multicolumn{7}{|l|}{ Vertebrates } \\
\hline Aratrakorn et al. & 2006 & Birds & 108 & 41 & 21 & 0.19 \\
\hline Bernard et al. & 2009 & $\begin{array}{l}\text { Non-volant } \\
\text { small } \\
\text { mammals }\end{array}$ & 6 & 1 & 0 & 0.00 \\
\hline Danielsen and Heegaard & 1995 & Primates & 5 & 1 & 0 & 0.00 \\
\hline Danielsen and Heegaard & 1995 & Bats & 8 & 1 & 1 & 0.13 \\
\hline Fukuda et al. & 2009 & Bats & 19 & 5 & 4 & 0.21 \\
\hline Gillespie et al. & 2012 & Amphibians & 21 & 12 & 10 & 0.48 \\
\hline Glor et al. & 2001 & Lizards & 11 & 5 & 4 & 0.36 \\
\hline Juliani & 2010 & Bats & 9 & 7 & 3 & 0.33 \\
\hline Peh et al. & 2005,2006 & Birds & 159 & 40 & 36 & 0.23 \\
\hline Azhar et al. & 2011 & Birds & 194 & 55 & 49 & 0.25 \\
\hline Mean & & & & & & 0.22 \\
\hline SD & & & & & & 0.15 \\
\hline $\mathrm{n}$ & & & & & & 10 \\
\hline $95 \% \mathrm{Cl}$ & & & & & & 0.09 \\
\hline
\end{tabular}




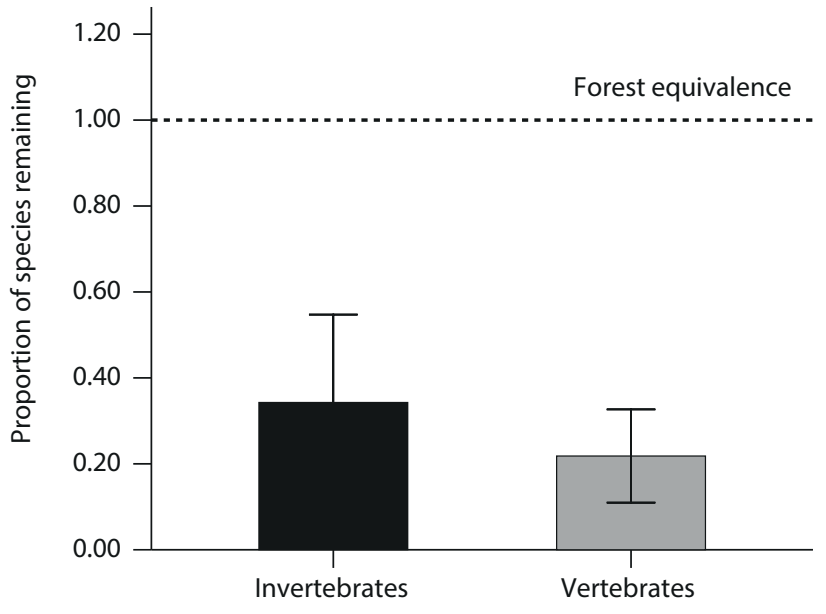

Figure 9. Mean proportion of shared species between oil palm plantation and forest with $95 \%$ confidence intervals. Data were standardized by the total number of species recorded in forest (the number of forest species $=1$ ).

\subsection{Narrative synthesis}

\subsubsection{Biodiversity in industrial versus smallholder plantations}

Only one study (Azhar et al. 2011) addressed differences in species richness and community composition between smallholder and industrial plantations. The results showed that, on average, smallholdings with mixed-age stands supported higher bird species richness than industrial plantation estates that had uniform age structure (range from $<6$ years old to $>25$ years old). The average dissimilarity of bird assemblages between the plantation estates and smallholdings was 47.6\%. However, since yields were not taken into account in the analyses it is not known whether the impact is similar when compared for equivalent amounts of fuel produced under different management systems.

\subsubsection{Explanatory factors for differences in species richness and community composition}

Only four studies had statistically analyzed the causes of differences in either species richness or community composition. For birds, the statistical analyses showed that increased ground vegetation and undergrowth height, as well as decreased canopy cover, were all correlated with higher species richness (Ibid). In addition, increased proximity to a forest patch, cumulative area of natural forest patches, and decreased isolation distance positively influenced bird species richness (Ibid). The role of food resources was speculated about in the discussion but not tested.

In the case of invertebrates, the hotter and drier conditions in oil palm plantations were the main cause of changes in community compositions (ants - Fayle et al. 2010; beetles - Chung et al. 2000; bees - Liow et al. 2001). Soil pH was a significant factor for isopods (Hassall et al. 2006), whereas the amount of leaf litter, tree and sapling densities, and plant species richness were significant factors for primary forest beetle species (Chung et al. 2000).

\subsubsection{Ecosystem function}

None of the studies had specifically looked at biodiversity-related ecosystem functions, such as pest control, pollination and soil processes that might have included supporting data. However, we found some discussions about concern for the continuity of pollination processes after expansion of oil palm habitats, and the changed communities between primary forest and other areas (Liow et al. 2001, and Shafie et al. 2011). In summary, these postulated that there would be negative consequences for forest regeneration if remaining forest areas cannot support large enough pollinator populations and pollinators are also absent in the surrounding oil palm matrix.

\subsubsection{Biofuel-related standards}

There were no studies that had tried to assess the impact of the standards on biodiversity. In fact, only a few of the studies reported whether the oil palm plantations studied were complying with standards. None of these had been structured to compare impacts before and after standards were applied (for a qualitative assessment of the standards see Appendix 4). 


\section{Discussion}

\subsection{Evidence of impact}

Although the number of studies that met the inclusion criteria was small relative to the amount of literature broadly related to the review topic, the evidence on species richness and community similarity from the included studies showed clearly that oil palm plantations have reduced species richness compared with primary and secondary forests, and the composition of species assemblage changes significantly after forest conversion to oil palm plantation. Species-specific responses would be expected to vary, but based on the studies included in the review, regardless of the taxa, forest specialists do not, in general, succeed in oil palm plantations. The findings are consistent with previous reviews that have addressed similar questions (Fitzherbert et al. 2008; Koh and Wilcove 2008; Danielsen et al. 2009; Foster et al. 2011).

With respect to abundance, responses appear to vary depending on species and there is no clear overall effect in one direction. When the abundance results are considered in light of the results on species richness and similarity, it appears that certain invertebrate species, e.g. generalist species, increase in abundance after forest conversion whereas others decline. However, it is possible that the responses may differ for vertebrates, as none of the studies in the meta-analysis looked at abundance of vertebrate taxa in forest compared with plantation.

\subsection{Reasons for variation in impact}

The variation in effect sizes observed in the metaanalysis most likely reflects different ecological requirements of different taxa and different species within these taxa. Part of the variance in the effect sizes was due to real differences between taxa rather than general heterogeneity, but the small number of studies included in the analyses did not warrant further exploration, mainly because the cases could not be categorized based on a taxon.

Both temporal and spatial aspects of sampling can create variation in effect sizes, which is why the importance of scale has been emphasized in biodiversity studies (Hamer and Hill 2000). As none of the studies addressed biodiversity changes at the landscape level, scale-dependent variation in effect sizes could not be evaluated. Variation in impacts due to seasonality could not be evaluated because the available evidence was based on shortterm data collection.

The small number of studies did not allow us to conduct quantitative examination of the importance of environmental variables, or variables related to plantation management, such as clearing of ground vegetation or type of plantation ownership (smallholdings versus industrial estates). However, there was an indication that both types of variables had some effect (Chung et al. 2000, Liow et al. 2001, Aratrakorn et al. 2006, Hassall et al. 2006, Fayle et al. 2010, and Azhar et al. 2011) and probably contribute to variation in the effect sizes, as they are most unlikely to be constant from one area to another, or even constant temporally within the same area (for example, because management practices can differ between plantations).

There are also natural processes such as competition and predation that can influence the results and create variation. Competitive interactions were mentioned, though not analysed, in one of the studies (Fayle et al. 2010), but in general the influence of competition and predation were not reported. 


\subsection{Review limitations}

This review was based on only one crop, oil palm, with the majority of studies conducted in Malaysia and almost half of the studies in one Malaysian State. We would therefore not want to generalize our findings outside Southeast Asia.

When biodiversity is compared across natural and human-modified landscapes, there are many factors that can limit the generality of conclusions. Variability is an inherent component of biological systems, and human actions in the studied area as well as in the surrounding landscape can add further variability. One way to account for the variability is to include replication in the study design. Unfortunately, the majority of the studies included in the review included insufficient reporting of study conditions and details, or were poorly replicated or pseudo-replicated, which is common for biodiversity studies (Ramage et al. 2013). Although it is assumed that site comparison studies pair sites that share common attributes, this is not necessarily the case in practice. For example, only a few studies reported on the type of surrounding landscape or on the original vegetation. A number of unreported factors could therefore have contributed to the true effect sizes.

One significant limitation of the review is the lack of landscape level comparisons. Although comparing production areas with forest provides information of the extent of losses at the management unit level, it does not provide information about whether there is a loss in biodiversity at the landscape level. A landscape level approach would be required to incorporate differences between different landscape mosaics, as well as their historical backgrounds, into the analysis.

The 25 papers identified in this review compared oil palm plantations with forest. However for us to understand the differences between management systems and the link between management practices and biodiversity, we also need studies that make further comparisons between differently-managed areas. In this review such stratification was not possible because of the dearth of information. To move beyond comparing forest ecosystem with oil palm plantation, there is a need to conduct a robust impact evaluation of differently-managed areas.

The lack of information also prevented analysis of species or taxa-specific responses, which is a limitation of the current review. We combined different taxa in the analyses out of necessity, but we recognize that this can mask responses that are specific to certain groups or taxa. As metrics of biodiversity, species richness and abundance suffer from a similar kind of blindness as they consider all the species and individuals to be equal. The inclusion of community similarity in the review alleviates this limitation to some extent.

Publication bias cannot be wholly discounted, even though there are grounds to assume that it is not a significant problem for this body of literature. Grey and unpublished literature was extensively searched in several languages. Correlations between sample sizes and effects were not significant. Finally, considering the nature of the subject, non-significant findings have the same value as significant ones. 


\section{Conclusions}

\subsection{Potential implications for biodiversity conservation, policy, and plantation management}

The available evidence suggests that oil palm plantations support lower species richness than primary or secondary forest. Also, forest conversion to oil palm plantation leads to significant changes in community composition, which indicates that oil palm plantations are not suitable habitats for the majority of forest species. Unfortunately, very little information was available about the impacts of smallholder plantations or different standards, which makes it difficult to evaluate their usefulness.

\subsection{Potential implications for research}

The review identified several knowledge gaps about the impacts of biofuel crop cultivation on biodiversity and ecosystem function:

- Landscape level studies that would contribute better knowledge of the impacts at larger scales beyond simple habitat comparisons.

- Research on how reduced species richness or changes in community composition affect ecosystem functions. The lack of knowledge about this topic was also a conclusion of a recent review by Foster et al. (2011).

- Research on differences in biodiversity and ecosystem function in response to different production systems, (smallholdings versus industrial estates) and different management practices (certified and non-certified plantations).

- Studies on jatropha and soybean and oil palm beyond Malaysia.

To provide a sound evidence base for land use management decisions, future studies should pay careful attention to study designs, for example by defining the sampling population of land uses and then using stratified randomization to select study sites, as well as ensuring that seasonality effects are taken into account, and that there are enough replicates. Methodologies should be shared across plantations, users and experiments to identify groups for future monitoring and to make use of crowdsourced identification (e.g. Ispot, http:// www.ispotnature.org/.)

Finally, there are a number of recommendations for authors and publishers that relate to the reporting of biodiversity studies. First, descriptions of methods should be more detailed, including exact explanations for site selection, and descriptions of plantation sizes, ages and management histories. Failure to include such basic information precludes subsequent analysis, and lowers the value of such studies for guiding policy. Second, details of management practices are needed, particularly whether the plantation is certified, and details about which standards are adhered to within the plantation. Finally, crop yields in plantations under different management regimes should be reported to facilitate comparisons that can support policy and decision making. 


\section{References}

Aerts R and Honnay O. 2011. Forest restoration, biodiversity and ecosystem functioning. $B M C$ ecology 11(1): 29.

Aratrakorn S, Thunhikorn S and Donald PF. 2006. Changes in bird communities following conversion of lowland forest to oil palm and rubber plantations in southern Thailand. Bird Conservation International 16(1): 71-82.

Arnqvist G and Wooster D. 1995. Meta-analysis: Synthesizing research findings in ecology and evolution. Trends in Ecology \& Evolution 10(6): 236-240.

Azhar B, Lindenmayer DB, Wood J, Fischer J, Manning A, McElhinny C and Zakaria M. 2011. The conservation value of oil palm plantation estates, smallholdings and logged peat swamp forest for birds. Forest Ecology and Management 262(12): 2306-2315.

Bernard H, Fjeldså J and Mohamed M. 2009. A case study on the effects of disturbance and conversion of tropical lowland rain forest on the non-volant small mammals in north Borneo: Management implications. Mammal study 34(2): 85-96.

Borenstein M, Hedges LV, Higgins JP and Rothstein HR 2011. Introduction to metaanalysis. John Wiley \& Sons.

Brühl C. 2001. Leaf litter ant communities in tropical lowland rain forests in Sabah, Malaysia: effects of forest disturbance and fragmentation. $\mathrm{PhD}$ Thesis. Julius Maximilian University of Würzburg, Germany.

Brühl CA and Eltz T. 2010. Fuelling the biodiversity crisis: Species loss of grounddwelling forest ants in oil palm plantations in Sabah, Malaysia (Borneo). Biodiversity and Conservation 19(2): 519-529.

Chang M, Hii J, Buttner P and Mansoor F. 1997. Changes in abundance and behaviour of vector mosquitoes induced by land use during the development of an oil palm plantation in Sarawak. Transactions of the Royal Society of Tropical Medicine and Hygiene 91(4): 382-386.
Chey VK. 2006. Impacts of forest conversion on biodiversity as indicated by moths. Malayan Nature Journal 57(4): 383-418.

Chung A, Eggleton P, Speight M, Hammond P and Chey VK. 2000. The diversity of beetle assemblages in different habitat types in Sabah, Malaysia. Bulletin of entomological research 90(06): 475-496.

Cooper H, Hedges LV and Valentine JC. 2009. The handbook of research synthesis and metaanalysis. Russell Sage Foundation.

Danielsen F, Beukema H, Burgess ND, Parish F, Bruehl CA, Donald PF, Murdiyarso D, Phalan B, Reijnders L and Struebig M. 2009. Biofuel plantations on forested lands: Double jeopardy for biodiversity and climate. Conservation Biology 23(2): 348-358.

Davis AL and Philips TK. 2005. Effect of deforestation on a southwest Ghana dung beetle assemblage (Coleoptera: Scarabaeidae) at the periphery of Ankasa conservation area. Environmental Entomology 34(5): 1081-1088.

Dumbrell AJ and Hill JK. 2005. Impacts of selective logging on canopy and ground assemblages of tropical forest butterflies: Implications for sampling. Biological Conservation 125(1): 123-131.

Edwards DP, Hodgson JA, Hamer KC, Mitchell SL, Ahmad AH, Cornell S J and Wilcove DS. 2010. Wildlife-friendly oil palm plantations fail to protect biodiversity effectively. Conservation Letters 3: 236-242.

Edwards P, Clarke M, DiGuiseppi C, Pratap S, Roberts I and Wentz R. 2002. Identification of randomized controlled trials in systematic reviews: Accuracy and reliability of screening records. Statistics in medicine 21(11): 16351640.

FAO 2008. Forests and energy. FAO Forestry Paper 154, Food and Agriculture Organization of the United Nations.

Fayle TM, Turner EC, Snaddon JL, Chey VK, Chung AY, Eggleton P and Foster WA. 2010. 
Oil palm expansion into rain forest greatly reduces ant biodiversity in canopy, epiphytes and leaf-litter. Basic and Applied Ecology 11(4): 337-345.

Feintrenie L, Chong WK and Levang P. 2010. Why do farmers prefer oil palm? Lessons learnt from Bungo district, Indonesia. SmallScale Forestry 9(3): 379-396.

Fitzherbert EB, Struebig MJ, Morel A, Danielsen F, Brühl CA, Donald PF and Phalan B. 2008. How will oil palm expansion affect biodiversity? Trends in ecology \& evolution 23(10): 538-545.

Foster WA, Snaddon JL, Turner EC, Fayle TM, Cockerill TD, Ellwood MF, Broad GR, Chung AY, Eggleton P and Khen CV. 2011. Establishing the evidence base for maintaining biodiversity and ecosystem function in the oil palm landscapes of South East Asia. Philosophical Transactions of the Royal Society B: Biological Sciences 366(1582): 3277-3291.

Fukuda D, Tisen OB, Momose K and Sakai S. 2009. Bat diversity in the vegetation mosaic around a lowland dipterocarp forest of Borneo. Raffles Bulletin of Zoology 57(1): 213-221.

Gillespie GR, Ahmad E, Elahan B, Evans A, Ancrenaz M, Goossens B and Scroggie MP. 2012. Conservation of amphibians in Borneo: Relative value of secondary tropical forest and non-forest habitats. Biological Conservation 152: 136-144.

Glor R, Flecker A, Benard M and Power A. 2001. Lizard diversity and agricultural disturbance in a Caribbean forest landscape. Biodiversity \& Conservation 10: 711-723.

Hamer K and Hill J. 2000. Scale-dependent effects of habitat disturbance on species richness in tropical forests. Conservation Biology 14(5): 1435-1440.

Hamer K, Hill J, Benedick S, Mustaffa N, Sherratt T and Maryati M. 2003. Ecology of butterflies in natural and selectively logged forests of northern Borneo: The importance of habitat heterogeneity. Journal of Applied Ecology 40(1): 150-162.

Hashim NR, Jusoh W, Akmal WF, Nasir M and Safre MN. 2009. Ant diversity in a Peninsular Malaysian mangrove forest and oil palm plantation. Asian Myrmecology 3: 5-8.

Hassall M, Jones DT, Taiti S, Latipi Z, Sutton SL and Mohammed M. 2006. Biodiversity and abundance of terrestrial isopods along a gradient of disturbance in Sabah, East
Malaysia. European Journal of Soil Biology 42: S197-S207.

Juliani NS, Anuar MSS, Salmi ALN, Munira AN and Liyana KN. 2011. Diversity pattern of bats at two contrasting habitat types along Kerian River, Perak, Malaysia. Tropical Life Sciences Research 22: 13-22.

Koh LP and Ghazoul J. 2008. Biofuels, biodiversity, and people: Understanding the conflicts and finding opportunities. Biological conservation 141(10): 2450-2460.

Koh LP and Wilcove DS. 2008. Is oil palm agriculture really destroying tropical biodiversity? Conservation letters 1(2): 60-64.

Laurance WF, Koh LP, Butler R, Sodhi NS, Bradshaw CJ, Neidel JD, Consunji $\mathrm{H}$ and Mateo Vega J. 2010. Improving the performance of the Roundtable on Sustainable Palm Oil for nature conservation. Conservation Biology 24(2): 377-381.

Lewandowski I and Faaij AP. 2006. Steps towards the development of a certification system for sustainable bio-energy trade. Biomass and Bioenergy 30(2): 83-104.

Liow LH, Sodhi NS and Elmqvist T. 2001. Bee diversity along a disturbance gradient in tropical lowland forests of south-east Asia. Journal of Applied Ecology 38(1): 180-192.

Lucey JM and Hill JK 2012. Spillover of insects from rain forest into adjacent oil palm plantations. Biotropica 44(3): 368-377.

Nichols E, Larsen T, Spector S, Davis A, Escobar F, Favila M and Vulinec K. 2007. Global dung beetle response to tropical forest modification and fragmentation: A quantitative literature review and meta-analysis. Biological Conservation 137(1): 1-19.

Peh KSH, Jong JD, Sodhi NS, Lim SLH and Yap CAM. 2005. Lowland rainforest avifauna and human disturbance: persistence of primary forest birds in selectively logged forests and mixed-rural habitats of southern Peninsular Malaysia. Biological Conservation 123: 489505.

Peh KSH, Sodhi NS, De Jong J, Sekercioglu CH, Yap CAM and Lim SLH. 2006. Conservation value of degraded habitats for forest birds in southern Peninsular Malaysia. Diversity and Distributions 12(5): 572-581.

Phalan B. 2009. The social and environmental impacts of biofuels in Asia: An overview. Applied Energy 86: S21-S29. 
Pullin AS and Knight TM. 2003. Support for decision making in conservation practice: An evidence-based approach. Journal for Nature Conservation 11(2): 83-90.

Rajagopal D and Zilberman D. 2007. Review of environmental, economic and policy aspects of biofuels. World Bank Publications.

Ramage BS, Sheil D, Salim HM, Fletcher C, Mustafa NZA, Luruthusamay JC, Harrison RD, Butod E, Dzulkiply AD and Kassim AR. 2013. Pseudoreplication in tropical forests and the resulting effects on biodiversity conservation. Conservation Biology 27(2): 364372.

Room PM. 1975. Diversity and organization of the ground foraging ant faunas of forest, grassland and tree crops in Papua New Guinea Australian Journal of Zoology 23:71-89.

Rosenthal R, Cooper H and Hedges L. 1994. Parametric measures of effect size. The handbook of research synthesis: 231-244.
Savilaakso S, Laumonier Y, Guariguata MR and Nasi R. 2013. Does production of oil palm, soybean, or jatropha change biodiversity and ecosystem functions in tropical forests? Environmental Evidence 2(1): 17.

Shafie NJ, Sah SAM, Latip NSA, Azman N Mand Khairuddin NL. 2011. Diversity pattern of bats at two contrasting habitat types along Kerian River, Perak, Malaysia. Tropical life sciences research 22(2): 13.

Sheldon FH, Styring A and Hosner PA. 2010. Bird species richness in a Bornean exotic tree plantation: A long-term perspective. Biological conservation 143(2): 399-407.

Vaessen T, Verwer C, Demies M, Kaliang H and Van Der Meer P. 2011. Comparison of termite assemblages along a landuse gradient on peat areas in Sarawak, Malaysia. Journal of Tropical Forest Science: 196-203. 


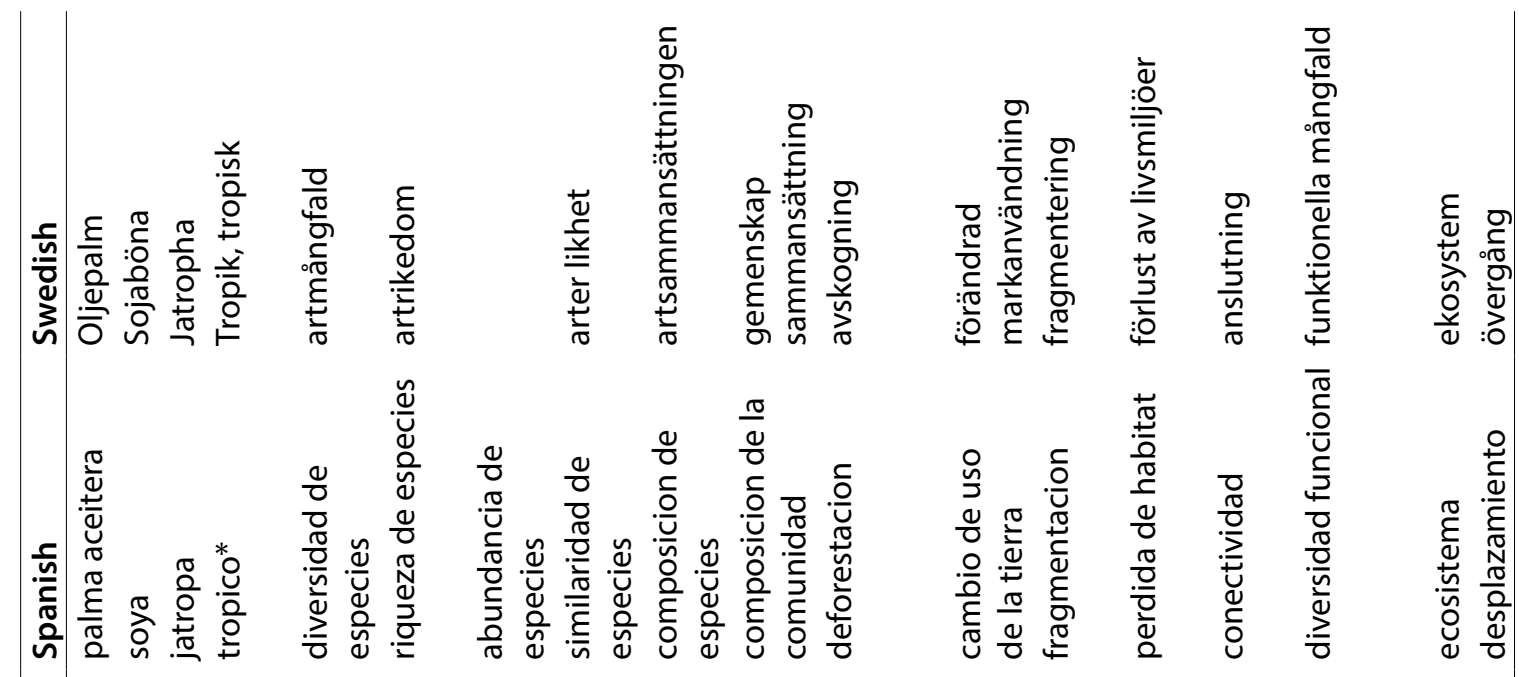

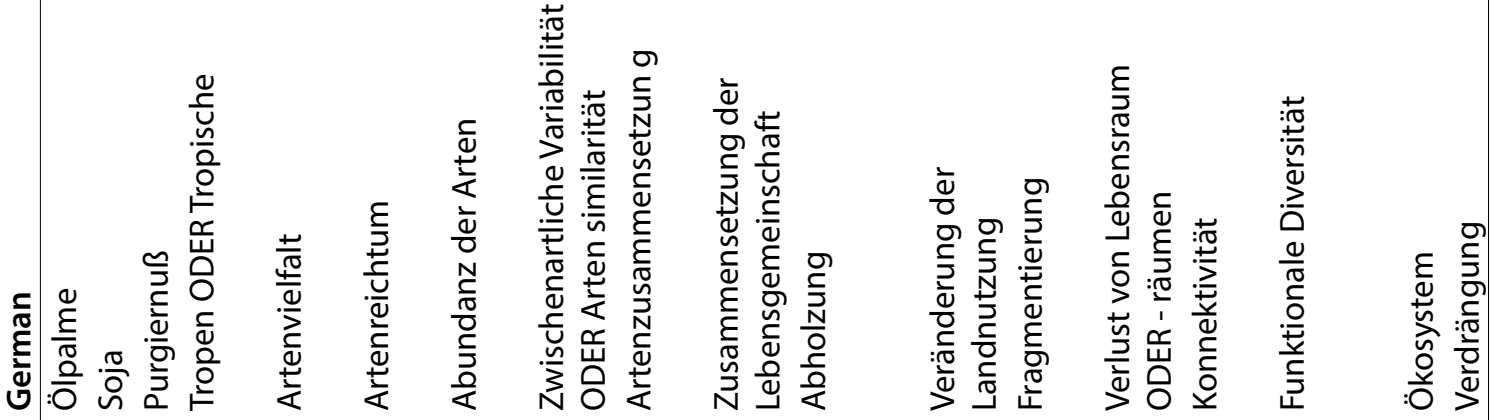

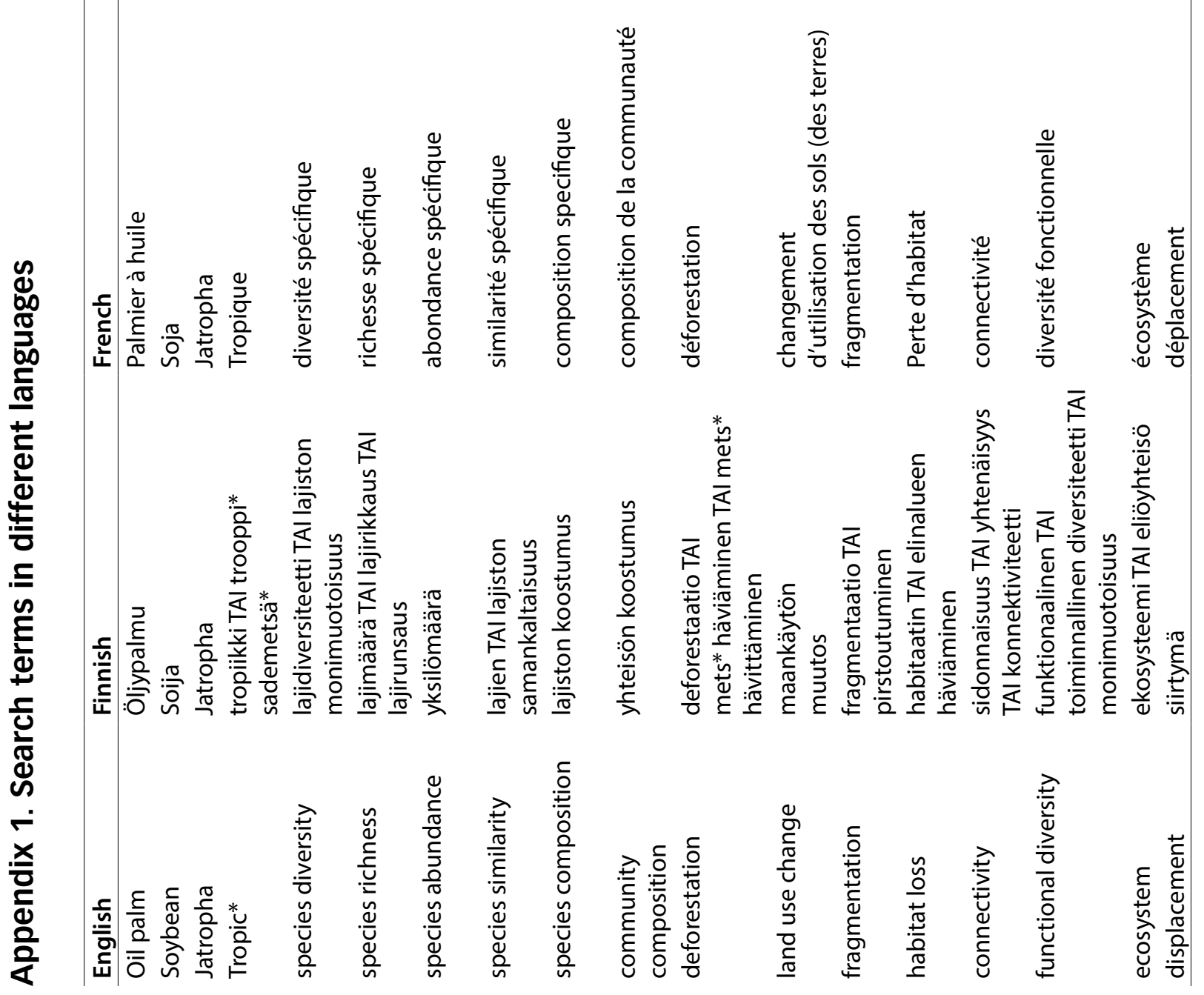




\section{Appendix 2. Equations used in the quantitative meta-analysis}

Hedges' $d$ :

$$
d=\frac{\bar{X}_{c}-\bar{X}_{e}}{S} J
$$

where $\bar{X}_{c}$ is the mean species richness/abundance of primary forest, $\bar{X}_{e}$ is mean species richness/ abundance of biofuel crop plantation, $S$ is the pooled standard deviation, and $J$ is the correction factor for a small sample bias:

$$
S=\sqrt{\frac{\left(N^{e}-1\right)\left(S^{E}\right)^{2}+\left(N^{c}-1\right)\left(s^{C}\right)^{2}}{N^{e}+N^{c}-2}}
$$

and

$$
J=1-\frac{3}{4\left(N^{c}+N^{e}-2\right)-1}
$$

where $N^{c}$ is the sample size for primary forest, $N^{e}$ is sample size for biofuel crop plantation, $s^{C}$ is the standard deviation for the primary forest, and $s^{E}$ is the standard deviation for biofuel crop plantation.

The variance of Hedges's $d$ :

$$
v_{d}=\frac{N^{c}+N^{e}}{N^{c} N^{e}}+\frac{d^{2}}{2\left(N^{c}+N^{e}\right)}
$$

In cases where the estimates of mean and standard deviation were not provided but a $t$-statistic was, this was used to calculate Hedges' $d$ by transforming the $t$-statistic first to Hedges' $g$ and then the $g$ to Hedges' $d$. The equation for Hedges' $g$ when the sample sizes are equal is:

$$
g=\frac{2 t}{\sqrt{N}}
$$

where $N$ is the total sample size $\left(N^{c}+N^{e}\right)$.

And for Hedges' d:

$$
d=g\left(1-\frac{3}{4\left(N^{c}+N^{e}-2\right)-1}\right)
$$

The Q-statistic:

$$
Q=\sum_{i=1}^{k} W_{i}\left(Y_{i}-M\right)^{2}
$$

where $W_{i}$ is the study weight $\left(1 / V_{i}\right), V_{i}$ is the within-study sampling error variance, $Y_{i}$ is the study effect size, $\mathrm{M}$ is the summary effect, and $\mathrm{k}$ is the number of studies.

The $I^{2}$-statistic:

$$
I^{2}=\frac{(Q-d f)}{Q} \times 100 \%
$$




\section{Appendix 3. List of studies included in the review}

1. Aratrakorn $S$, Thunhikorn $S$ and Donald PF. 2006. Changes in bird communities following conversion of lowland forest to oil palm and rubber plantations in southern Thailand. Bird Conservation International 16: 71-82.

2. Azhar B, Lindenmayer DB, Wood J, Fischer J, Manning A, McElhinny $\mathrm{C}$ and Zakaria M. 2011. The conservation value of oil palm plantation estates, smallholdings and logged peat swamp forest for birds. Forest Ecology and Management 262: 2306-2315.

3. Bernard H, Fjeldså J and Mohamed M. 2009. A case study on the effects of disturbance and conversion of tropical lowland rain forest on the non-volant small mammals in north Borneo: Management implications. Mammal Study 34: 85-96.

4. Brühl C and Eltz T. 2010. Fuelling the biodiversity crisis: species loss of grounddwelling forest ants in oil palm plantations in Sabah, Malaysia (Borneo). Biodiversity and Conservation 19: 519-529.

5. Chang, MS, Hii J, Buttner P and Mansoor F. 1997. Changes in abundance and behaviour of vector mosquitoes induced by land use during the development of an oil palm plantation in Sarawak. Transactions of the Royal Society of Tropical Medicine and Hygiene 91: 382-386.

6. Chey VK. 2006. Impacts of forest conversion on biodiversity as indicated by moths. Malayan Nature Journal 57: 383-418.

7. Chung AYC, Eggleton P, Speight MR, Hammond PM and Chey VK. 2000. The diversity of beetle assemblages in different habitat types in Sabah, Malaysia. Bulletin of Entomological Research 90: 475-496.

8. Danielsen F and Heegaard M. 1995. Impact of logging and plantation development on species diversity: a case study from Sumatra. In SANDBUKT, Ø. (ed.) Management of tropical forests: towards an integrated perspective. Oslo: Centre for Development and the Environment. University of Oslo.
9. Davis ALV and Philips TK. 2005. Effect of deforestation on a southwest Ghana dung beetle assemblage (Coleoptera : Scarabaeidae) at the periphery of Ankasa conservation area. Environmental Entomology 34: 1081-1088.

10. Edwards DP, Hodgson JA, Hamer KC, Mitchell SL, Ahmad AH, Cornell SJ and Wilcove DS. 2010. Wildlife-friendly oil palm plantations fail to protect biodiversity effectively. Conservation Letters 3: 236-242.

11. Fayle TM, Turner EC, Snaddon JL, Chey VK, Chung AYC, Eggleton P and Foster WA. 2010. Oil palm expansion into rain forest greatly reduces ant biodiversity in canopy, epiphytes and leaf-litter. Basic and Applied Ecology 11: 337-345.

12. Fukuda D, Tisen OB, Momose K and Sakai S. 2009. Bat diversity in the vegetation mosaic around a lowland dipterocarp forest of Borneo. The Raffles bulletin of Zoology 57: 213-221.

13. Gillespie GR, Ahmad E, Elahan B, Evans A, Ancrenaz M, Goossens B and Scroggie MP. 2012. Conservation of amphibians in Borneo: Relative value of secondary tropical forest and non-forest habitats. Biological Conservation 152: 136-144.

14. Glor R, Flecker A, Benard MF and Power A. 2001. Lizard diversity and agricultural disturbance in a Caribbean forest landscape. Biodiversity and Conservation 10: 711-723.

15. Hashim NR, Jusoh WFAW and Nasir MNSM. 2010. Ant diversity in a Peninsular Malaysian mangrove forest and oil palm plantation. Asian Myrmecology 3: 5-8.

16. Hassall M, Jones DT, Taiti S, Latipi Z, Sutton SL and Mohammed M. 2006. Biodiversity and abundance of terrestrial isopods along a gradient of disturbance in Sabah, East Malaysia. European Journal of Soil Biology 42: S197-S207.

17. Juliani NS, Anuar MSS, Salmi ALN, Munira AN and Liyana KN. 2011. Diversity pattern of bats at two contrasting habitat types along Kerian River, Perak, Malaysia. Tropical Life Sciences Research 22: 13-22. 
18. Koh LP and Wilcove DS. 2008. Is oil palm agriculture really destroying tropical biodiversity? Conservation Letters 1: 60-64.

19. Liow LH, Sodhi NS and Elmqvist T. 2001. Bee diversity along a disturbance gradient in tropical lowland forests of south-east Asia. Journal of Applied Ecology 38: 180-192.

20. Lucey JM and Hill JK. 2012. Spillover of insects from rain forest into adjacent oil palm plantations. Biotropica 44: 368-377.

21. Peh KSH, Jong JD, Sodhi NS, Lim S L-H and Yap, C A-M. 2005. Lowland rainforest avifauna and human disturbance: persistence of primary forest birds in selectively logged forests and mixed-rural habitats of southern Peninsular Malaysia. Biological Conservation 123: 489-505.
22. Peh KSH, Sodhi NS, De Jong J, Sekercioglu CH, Yap, C A-M and Lim S L-H. 2006. Conservation value of degraded habitats for forest birds in southern Peninsular Malaysia. Diversity and Distributions 12: 572-581.

23. Room PM. 1975. Diversity and organization of the ground foraging ant faunas of forest, grassland and tree crops in Papua New Guinea. Australian Journal of Zoology 23: 7189.

24. Sheldon FH, Styring A and Hosner PA. 2010. Bird species richness in a Bornean exotic tree plantation: A long-term perspective. Biological Conservation 143: 399-407.

25. Vaessen T, Verwer C, Demies M, Kaliang H and Van Der Meer PJ. 2011. Comparison of termite assemblages along a landuse gradient on peat areas in Sarawak, Malaysia. Journal of Tropical Forest Science, 23: 196-203. 


\section{Appendix 4. Qualitative assessment of standards related to oil palm, jatropha, and soybean}

The most recent versions of eight standards were considered (Table 1). Two of them are crop specific (RSPO, RTRS), a further two address biofuels only (EU-RES-D, RSB), and the rest are more general agricultural or environment management standards. All except EU-RES-D are voluntary and it should be noted that the EU-RED-D can be implemented through these voluntary certification schemes. The only mandatory aspects of the EU-RES-D relate to accounting rules for greenhouse gas emissions and certain other requirements, such as areas where production of biofuels is not allowed to take place.

To assess the standards several keywords that either matched directly or were linked to the search terms of the review were chosen. Those keywords were then searched within the standards based on the following categories:
- not mentioned,

- mentioned,

- mentioned and judged sufficient to prevent and mitigate negative effects on biodiversity,

- mentioned and included if identified as a "High Conservation Value" (HCV) area,

- multiple provisions for avoidance, but no strict prohibition included,

- not applicable.

If the keyword was mentioned in the criteria, a qualitative evaluation was conducted of the potential of these criteria to mitigate the impacts of crop cultivation on biodiversity.

Information was taken from principles and criteria stated in each standard, with reference to primary guidance documents as needed.

Table 1. Different standards related to biofuel crop production.

\begin{tabular}{|c|c|c|}
\hline Abbreviation & Standard & Year published \\
\hline ISO & $\begin{array}{l}\text { Environmental management systems - Requirements with guidance } \\
\text { for use (14001:2004) by International Organization for Standardization }\end{array}$ & 2004 \\
\hline RSPO & $\begin{array}{l}\text { Roundtable on Sustainable Palm Oil (RSPO) Principles and Criteria for } \\
\text { Sustainable Palm Oil Production }\end{array}$ & 2007, updated 2013 \\
\hline IFC AC \& P & $\begin{array}{l}\text { International Finance Corporation (IFC) Environmental, Health, and } \\
\text { Safety Guidelines for Annual Crop Production; Environmental, Health, } \\
\text { and Safety Guidelines for Plantation Crop Production }\end{array}$ & 2007 \\
\hline EU-RES-D & $\begin{array}{l}\text { Directive } 2009 / 28 / E C \text { of the European Parliament and of the Council } \\
\text { of } 23 \text { April } 2009 \text { on the promotion of the use of energy from } \\
\text { renewable sources and amending and subsequently repealing } \\
\text { Directives } 2001 / 77 / E C \text { and } 2003 / 30 / E C\end{array}$ & 2009 \\
\hline RSB & $\begin{array}{l}\text { Roundtable on Sustainable Biofuels (RSB) Principles and Criteria, } \\
\text { version } 2.0\end{array}$ & 2010 \\
\hline SAN & Sustainable Agriculture Standard of Sustainable Agriculture Network & 2010 \\
\hline $\mathrm{RCA}$ & $\begin{array}{l}\text { ECOFYS: Responsible Cultivation Areas: Identification and certification } \\
\text { of feedstock production with a low risk of indirect effects }\end{array}$ & 2010 \\
\hline RTRS & $\begin{array}{l}\text { Roundtable on Responsible Soy Association (RTRS) Standard for } \\
\text { Responsible Soy Production } \\
\text { Version } 1.0\end{array}$ & 2010 \\
\hline
\end{tabular}


The main approach of the standards towards biodiversity conservation is to conserve habitats that are considered biodiversity rich or have otherwise significant biodiversity value. Five of the standards define the land type considered to have rich biodiversity (Table 2) and RTRS has plans to develop national-level biodiversity maps. High conservation value (HCV) areas are recognized by all except two of the standards (SAN, ISO) and their conversion is prohibited or conditionally prohibited; the RTRS and the RSB allow a limited exploitation of HCV areas on a condition that the HCVs they include are maintained (e.g. viable populations of endangered species). The EU-RES-D also prohibits conversion of areas that provide high carbon stock, wetlands, peatlands, and continuously forested areas that can also harbor significant biodiversity. Although the SAN standard does not refer to HCV areas, in practice it provides protection of those areas as it prohibits the destruction of any natural ecosystem from certification onwards. Protected areas are also explicitly mentioned as "no go" areas by almost all of the standards.

At the landscape level, the RSB and SAN standards specifically guide to maintain connectivity and the IFC guides to maintain the field borders as natural corridors among cultivated areas. Although conversion of certain areas is prohibited under the standards, only the RCA addresses indirect effects of land use change and provides guidance how to mitigate those effects. Similarly, habitat fragmentation is only addressed by the RSB.

At the species level, endangered and threatened species are protected by all of the standards. Species level is also addressed via the HCV concept where "forest areas containing globally, regionally or nationally significant large landscape level forests, contained within, or containing the management unit, where viable populations of most if not all naturally occurring species exist in natural patterns of distribution and abundance" are important to maintain, but otherwise maintaining viable species' populations is hardly mentioned. Furthermore, preventing or controlling hunting is mentioned only by three of the standards, the RSPO, the RTRS, and the SAN.

Ecosystem services and functions are often addressed through the HCV concept. The RTRS, the RSB and the SAN address them through explicit criteria and guidance on good management practices, whereas the IFC requires specific monitoring of soil health. The ecosystem functions most often addressed are related to water quality and soil erosion.

Environmental impact assessment (EIA) is required by all standards except the RCA and the EURES-D, which does not require it in the context of biodiversity, but refers to it in the context of greenhouse gas emissions. The RCA is focused on identifying suitable areas for environmentally and socially responsible production and thus, EIA falls outside of the scope of the concept. Among those standards that require EIA there are differences in the approach. For example, the RSB and the RSPO provide guidance on how and when to conduct an EIA, whereas the RTRS and the SAN are more general in their requirements. Monitoring is included in all the standards but approaches towards it differ. For example, the RTRS and the RSPO give guidance on indicators, whereas the SAN just notes that monitoring should be conducted to prove compliance or to show corrective action taken in non-compliance situations. Some standards also have different requirements for smallholders or groups, for example regarding the EIA. 


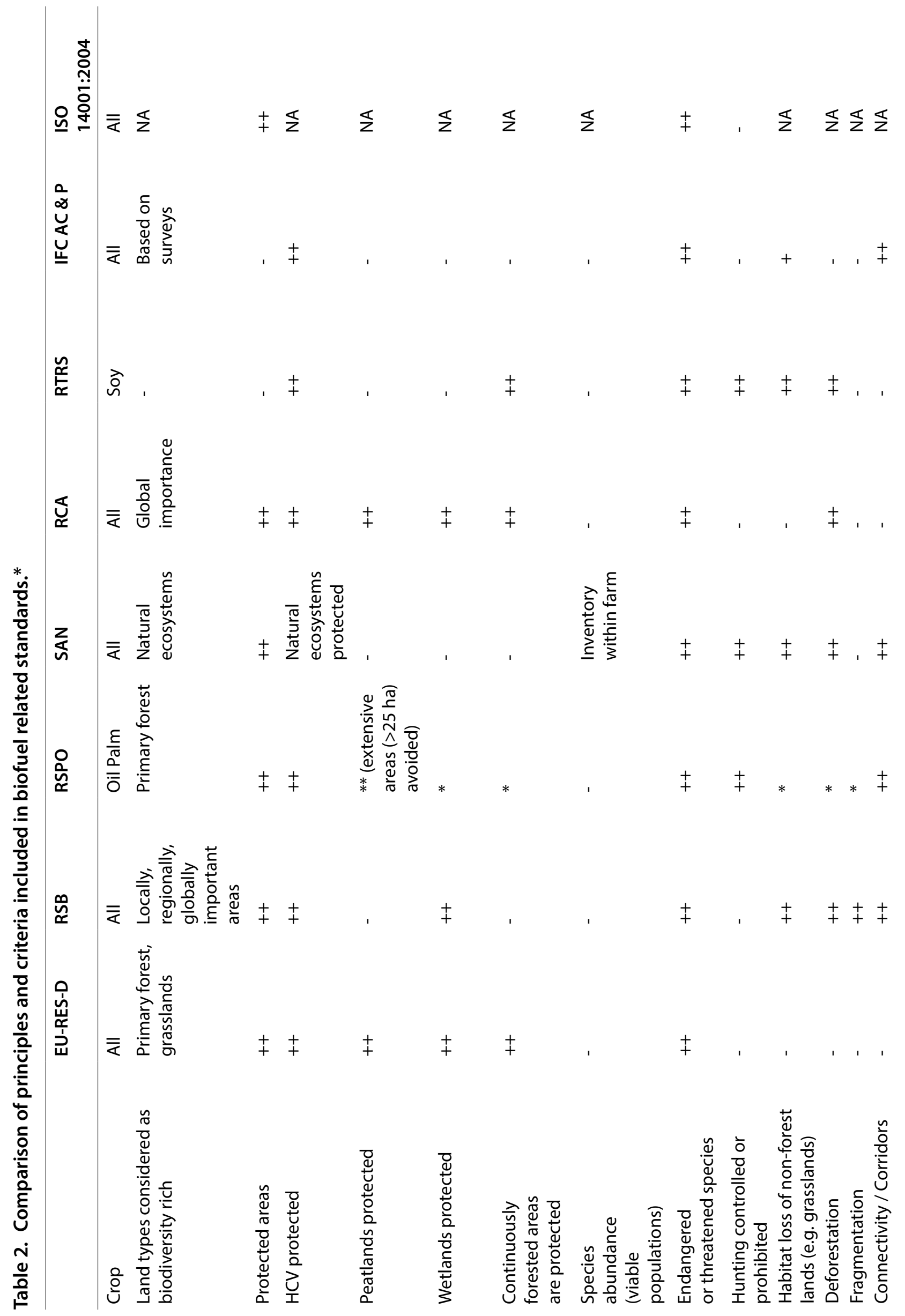




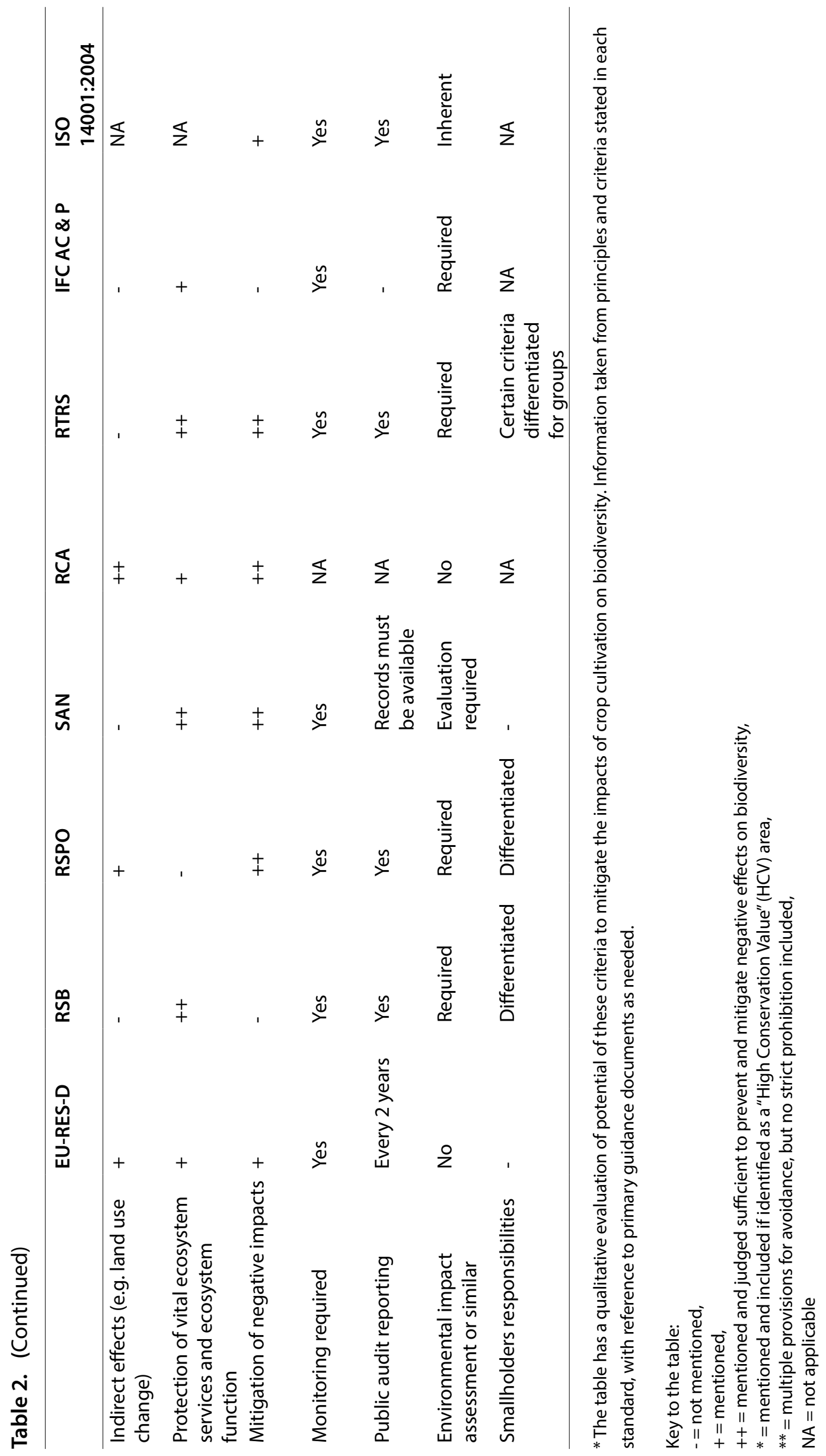



Background. During the past decade there has been a growing interest in bioenergy driven by concerns about global climate change, growing energy demand, and depleting fossil fuel reserves. The predicted rise in biofuel demand makes it important to understand the potential consequences of expanding biofuel cultivation. A systematic review was conducted on the biodiversity impacts of three first-generation biofuel crops (oil palm, soybean, and jatropha) in the tropics. The study focused on the impacts on species richness, abundance (total number of individuals or occurrences), community composition, and ecosystem functions related to species richness and community composition.

Methods. Literature was searched using an a priori protocol. Owing to a lack of available studies of biodiversity impacts from soybean and jatropha that met the inclusion criteria set out in the systematic review protocol, all analyses focused on oil palm. The impacts of oil palm cultivation on species richness, abundance, and community similarity were summarized quantitatively; other results were summarized narratively.

Results. The searches returned 9143 articles after duplicate removal of which 25 met the published inclusion criteria and were therefore accepted for the final review. Twenty of them had been conducted in Malaysia and two thirds were on arthropods. Overall, oil palm plantations had reduced species richness compared with primary and secondary forests, and the composition of species assemblages changed significantly after forest conversion to oil palm plantation. Abundance showed species-specific responses, and hence the overall abundance was not significantly different between plantations and forest areas. Only one study reported how different production systems (smallholdings versus industrial estates) affect biodiversity. No studies that examined the effects on ecosystem functions of reduced species richness or changes in community composition met the inclusion criteria. Neither were there studies that reported how areas managed under different standards (e.g. different certification systems) affect biodiversity and ecosystem function.

Conclusions. Our review suggests that oil palm plantations have reduced species richness compared with primary and secondary forests, and the composition of species assemblage changes significantly after forest conversion to oil palm plantation. Effects of different production systems on biodiversity and ecosystem function are clear knowledge gaps that should be addressed in future research.

\section{() BioMed Centra}

This publication was first published as Savilaakso et al. 2014 Environmental Evidence, 3:4 http://www.environmentalevidencejournal.org/content/3/1/4

\begin{tabular}{l|l} 
RESEARCH & This research was carried out by CIFOR as part of the CGIAR Research Program on Forests, Trees \\
PROGRAM on & $\begin{array}{l}\text { and Agroforestry (CRP-FTA). This collaborative program aims to enhance the management and } \\
\text { Forests, Trees and }\end{array}$ \\
uge of forests, agroforestry and tree genetic resources across the landscape from forests to farms. \\
CIFOR leads CRP-FTA in partnership with Bioversity International, CATIE, CIRAD, the International \\
Center for Tropical Agriculture and the World Agroforestry Centre.
\end{tabular}

\section{cifor.org}

CGIAR

